\title{
BUILDING IN FLUX
}

by

Matthew Robert Lahey, B.A.S.

A thesis submitted to The Faculty of Graduate Studies in partial fulfillment of

the requirements for the degree of

\section{MASTER OF ARCHITECTURE}

M.ARCH. (Professional)

Carleton University

OTTAWA, Ontario

(August 24th 2007)

(C) copyright

2007 Matthew Robert Lahey 


\section{ABSTRACT}

Division and segregation are inherent to the organization of space. Architecture, as an organizational device, has the ability to define an environment which accommodates certain actions and needs. The degree to which actions other than those originally planned for are permitted within the space is the prerogative of the architecture, which may be organized so as to exclude unsanctioned elements. The power of architecture to exclude creates a dichotomy between the "correct" usage of space, and that which is branded "deviant".

This thesis argues for a consideration of flux (as defined as a property of unexpected change) in building design as a means to undermining this dichotomy and the repressive power structure it supports. Architectonic manifestations of appropriation, transgression and exploration will be considered in relation to the exclusionist intents of mono-functionalist architecture. These disparate elements will be reconciled in the re-consideration of an architecture of power, the City Hall. 


\section{ACKNOWLEDGEMENTS}

Thank you to all those who have supported me throughout my education. 


\section{TABLE OF CONTENTS}

List of Illustrations $\quad$ v

List of Plates vii

List of Appendices viii

Introduction 1

I. Parcelling the Society of Control 3

i The Abstraction of Space 3

ii Abstract Space and Power 5

II. Stemming the Flow $\quad 10$

i Oscar Newman and Defensible Space 11

ii Mike Davis and the Heterotopia of Los Angeles 16

III. Housing the Flux of Civil Society 20

i Public Space and the Institutionalization of Conflict 21

ii Building Flux 25

IV. Case Studies $\quad 32$

i Former Ottawa City Hall 34

ii Parliamentary Quarters in Spreebogen 38

iii Nathan Philips Square and Toronto City Hall 42

iv Rideau Centre 46

V. Project $\quad 52$

i Intents and Outline 53

$\begin{array}{lll}\text { ii Nodes } & 63\end{array}$

$\begin{array}{ll}\text { Conclusions } & 79\end{array}$

Bibliography 


\section{LIST OF ILLUSTRATIONS}

\section{Fig. Description}

The Law vs. Ayook: Written vs. Oral History, Don Monet 6

Pruitt-Igoe housing complex, St.Louis, Missouri, Minoru Yamasaki 12

Pruitt-Igoe housing complex, St.Louis, Missouri, Minoru Yamasaki 12

Clarson Point housing project, New York City, Oscar Newman 13

Clarson Point housing project, New York City, Oscar Newman 13

Sketch illustrating the incorporation of surveillance into design, Oscar Newman 14

Diagram of Power and Segregation in Los Angeles, Mike Davis 17

Broadway Springs Centre, Los Angeles 18

Krystof Wodiczko, Homeless Vehicle Project

Superblock Residence, Brasilia $\quad 26$

Barrio, Brasilia 26

Cabrillo Marine Museum, San Pedro, California, Frank Gehry 28

Propaganda Film Studios, Los Angeles, Frank Israel 29

Crawford Residence, Montecito, California, Morphosis 31

Proposal for the League of Nations, Geneva, Le Corbusier 35

Former Ottawa City Hall, exterior perspective, John Bland 37

Former Ottawa City Hall, façade, John Bland 37

Former Ottawa City Hall, floor plans, John Bland 37

Proposal for the Berlin Parliamentary District Master Plan, aerial perspective, Morphosis 41

Nathan Philips Square and Toronto City Hall, plan, Viljo Revell 45

Nathan Philips Square with the Toronto City Hall in the background, Viljo Revell 45

Homeless at Toronto City Hall, exterior perspective 45

Rideau Centre, diagram of pedestrian movement 51

Rideau Centre, interior perspective $\quad 51$

Existing conditions on the proposed site, downtown Ottawa 57

Fragmentation and Dispersion of the Former Ottawa City Hall, downtown Ottawa 58 
New Ottawa City Hall, Canal Pedestrian Bridge, exterior perspective 68

$\begin{array}{ll}\text { New Ottawa City Hall, Tower, exterior perspective } & 70\end{array}$

New Ottawa City Hall, Mackenzie-King Pedestrian Walkway, exterior perspective 70

New Ottawa City Hall, Municipal Employee Office Block, exterior perspective 72

New Ottawa City Hall, Service Centre, exterior perspective 72

New Ottawa City Hall, Council Chambers, exterior perspective 75

New Ottawa City Hall, Council Chambers, interior perspective 75 


\section{LIST OF PLATES}

Plate Description

1 Conceptual Site Plan, New Ottawa City Hall

Site Section, New Ottawa City Hall 


\section{LIST OF APPENDICES}

\section{Appendix Description}


The task of the architect is to plan, devise and build. Planning is organization, and organization is segregation. At an elementary level the construction of segregation allows for barriers, both real and implicit, to separate individual people and groups, particular functions, and other facets of life from one another. The ability to control this segregation gives the ability to choose to accept certain things within certain boundaries; similarly, it offers the ability to exclude what is not wanted.

The purpose of this essay is twofold: to offer an overview of the mechanics of spatial exclusion and separation by examining some foundational principals, contemporary architectural manifestations of these principals, and critical responses these manifestations have engendered; and to investigate how these principals are upset and undermined through the introduction of flux, a property of change, decentralisation and impermanence. This thesis proposes an architecture which celebrates flux. 
The essay begins with a discussion of the fragmentation of society legitimised through principals

of abstract measurement, principals which prefer a homogenising empirical assessment of territory over an acknowledgement of qualities unique to a specific location. Social groups and lived spaces, now segregated from one another, are shown to be organised so as to best perpetuate the continuance of a social and economic system overseen by controlling powers. The second section will shift from the scale of broader society to the scale of individual built forms and examine how the previously discussed principals are manifested architecturally. The third section introduces the notion of flux and how it displaces the centrality, permanence and a-temporality of the controlling principals. Following the discussion of several relevant case studies, a project will be proposed which seeks to re-imagine an architecture of centralised power through the introduction of flux. 


\section{PARCELLING THE SOCIETY OF CONTROL}

This essay begins with an examination of a society of control effected through the spatial fragmentation of society. This fragmentation is spatially realized through the assignment of certain functions to particular places and spaces. This rigid and inflexible programmatic delineation proceeds from the application of the principles of spatial "abstraction". "Abstract" space compartmentalizes the rituals and actions of daily life into defined areas. The corollary of this is that rituals, actions, and people, not permitted in these areas are excluded.

\section{I.i The Abstraction of Space}

Nicholas Blomley asserts in his paper "Violence and Space" that the development of modern cartography, achieved through the imposition of the rationalizing Cartesian reference plane over the landscape, allowed for the quantification of space. The environment was now subject to an abstract system of metrics which allowed for a generalized understanding of not only one's immediate surroundings, but of all space. The application of this system followed a paradigm 
shift in thinking where beings had the ability to be measured quantifiably, and calculation was the fundamental determination of the world (Elden 15) ${ }^{1}$. Through advances in mapping technology beginning in the late Medieval period, these geometric systems began to be used to define territory, eventually leading to an understanding of the world through its calculability (Elden 16). The notion of the geometrically-conceived plan allowed for the parceling of land which, through the process of abstraction, ignored unique locational qualities which escape empirical measuring systems.

The application of abstract sets of geometric measures of space gave rise to "abstract space", a space which is understood in geometric terms, typically through the application of a uniform grid which acts as an organizational device. The rationality of mathematics allows for the grid's application to territory and space to appear natural and a priori, leading to an empirical understanding of the surrounding world. The ability to conceive of space as a collection of measured fragments, or sub-divisions, allows it to be divorced from its surroundings: as a fragment which may be studied unto itself, it no longer needs to be situated within a larger context. Empty of previous meanings and isolated from its greater context, abstract space may be filled and emptied with meaning and purpose, over and over again (Elden 15). Abstract space no longer has meaning inherent within it - it only gains meaning from without.
'Stuart Elden in his paper titled "Missing the Point" traces this development to Descartes' allencompassing algebraic systems which decoded and organized the lived world (Elden 15). 
Similar metrics may be applied to time as well to produce "abstract time". The advent of instruments which accurately measured set lengths of time allowed for abstract systems of time increments to be established. Alongside innovations such as widespread electric lighting and artificial heating and cooling, hours and minutes replaced other means of timekeeping that were specific to certain locales - the path of the sun and harvest times, for example, which are measures of time which depended upon the variances of the local environment. Time, as a marker of indeterminacy, is erased from abstract space - the systems of demarcation (both of time and of space) are understood as being eternal, without change (Gardiner 172).

\section{I.ii Abstract Space and Power}

Abstract space may be given a meaning, and it follows that the control of this meaning leads to control of the space. Paul Virilio notes in his 1975 work L'Insecurité du territoire that, "Geometry is the necessary foundation for a calculated expansion of state power into space and time" (qtd. in Elden 14). Tasked with the regulation and governance of large populations, the state $^{2}$ has used the organizing qualities of abstract space to facilitate its control over territory. Contemporary understandings of state sovereignty over territory is synonymous with control over an area which is contained within defined boundaries. The legitimization of a state is thus

\footnotetext{
2 The term "state" may be understood as a political association with effective dominion over a geographic territory, but it may also be useful to conceive of it as a de-centered complex of capillary and sometimes conflictual power relations that systematically create the larger effect of the state. The wielding of abstract space and time allows for a cohering of this unstable complex (Sparke 11).
} 
predicated upon state authority's unique control over the area it claims to govern ${ }^{3}$. Abstract time aids the legitimization of state power in this regard, as the power systems which govern the territory are assumed to be eternal and immutable, and are thus beyond reproach (Grönlund par. 12)

The 1987 Supreme Court trial between two First Nations associations - the Gitxsan and the Wetsuwet'en - and the federal government of Canada and the provincial government of British Columbia offers an example of the use abstract time and space in legitimising state control (Sparke 1). The arguments made against the First Nations claims of ownership over a disputed plot of land were based upon their inability to provide documentation which justified their claims using the same "language" of the European colonial maps of Canada. Orally transmitted songs of inhabitation, dreams and ceremony were not accepted as legitimate records of occupation in the land claims court, which only recognized the products of the tools of European cartography (Sparke 19). First Nations-claimed territories were deemed to be too ambiguous in their delineation and thus dismissed in the court - a dismissal which negated years of received history and practices which had governed the First Nations and their territories prior to the arrival of European settlers (Fig. 1). The courts, in overturning the land claims of the First Nations, remained subservient to the colonial cartographic methods

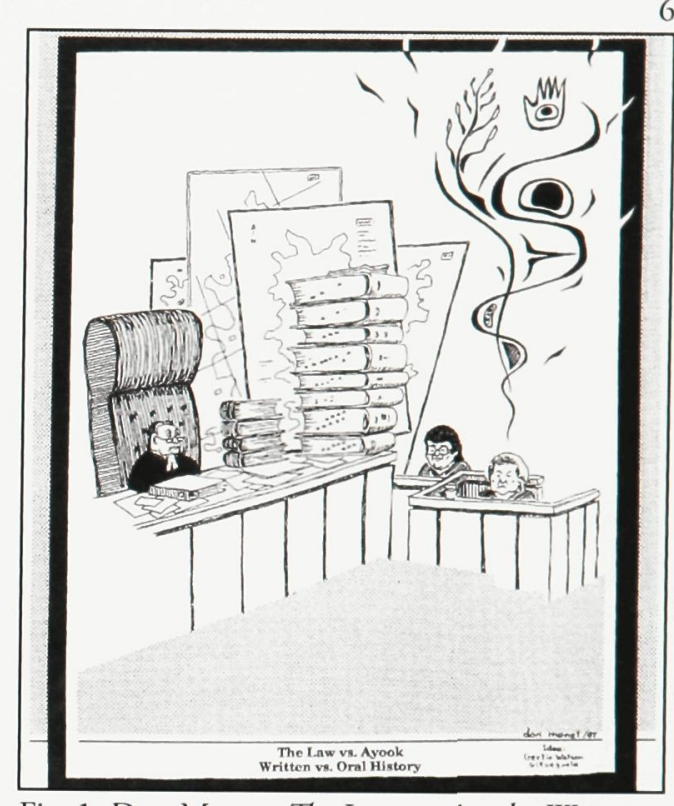

Fig. 1. Don Monet, The Law vs. Ayook: Written vs. Oral History, rpt. in Sparke 18.

A comment on different mapping techniques displayed at the First Nations Supreme Court case.

\footnotetext{
${ }^{3}$ This notion is often best elucidated through its inverse - when elements which are outside of a sovereign state's direct control act within a territory. Some critics of the continued presence of American military bases within Saudi Arabia, for example, claim that the state is merely a 'puppet regime' beholden to the interests of the United States, not their own.
} 
proffered by the state as legitimate and which abstracted away from social relations and history. These "legitimate" methods, in turn, legitimized the state's claims of control over the land - as well as it own very existence as a reified apparatus (Sparke 10).

The French theorist Henri Lefebvre observed the confluence of the state, abstract space, and capitalism. The commoditisation of space through its abstraction is observed to be effected first through the initial homogenisation of space, as examined above. This uniformity allows for the space to be easily subdivided, packaged and sold, as with any exchange item (Deutsche 77).

For Lefebvre, a bureaucratic society of controlled consumption seeks to transform the lived space occupied by those who it oversee into a profitable force of production. Through the auspices of neo-capitalism there is an attempt to functionalise, consolidate and structure everyday life. It is the prerogative of the bureaucratic state to dominate space, Lefebvre states, particularly the space of urban centres. The application of rationality subsumes the space into a homogenized whole - resulting in the negation of local particularities and differences which are supplanted by the needs of the capitalist system (Gardiner 90).

Reduced and simplified, space is rendered measurable not only geometrically, but socially 
as well (Grönlund par. 17). While abstraction renders the space homogeneous, it is also

fragmented into individual parts so that it may be bought and sold, as with a commodity. While interchangeable, these fragments may be acquired and aligned with the requisite hierarchies of control - thus centers and peripheries, upper- and lower-class spaces, and spaces of governing and the governed are created (Deutsche 75).

These spaces are imbued with incontrovertible meanings which pertain to specific roles in the overall society of consumption, such as spaces of productive work, spaces of leisure, and spaces of public gathering (Focault par.15). The establishment of isolated units is a means to ensure the smooth functioning of the overall system of production; like the individual components of a machine, each space is given a space use which ultimately serves to ensure the continued functioning of the capitalist engine. The separation of the spaces allows for the ease of administrative oversight, as well as control. Separation, effected through the policed maintenance of certain functions within established boundaries, ensures that certain actions are given to be 'proper' within certain spaces, and others are to be excluded. Through such classification of space we see the establishment of a system of values applied to not only the functions which are associated with these spaces, but also the people which occupy them as well. It is a system of classification which, in turn develops classes (with their own determinations 
of worth) to which the functions and its users become associated. Such determinations,

internalized by both the system and those residing within it, allow for segregation which ensures that the different spaces will not co-mingle (Grönlund par. 20). 


\section{STEMMING THE FLOW}

Given that certain actions are deemed unacceptable through spatial "abstraction", it follows that groups and individuals associated with those actions are to be removed from these regions. This section will explore the means in which this segregation is enforced through measures which are more discrete than security personnel or other means of overt regulation - means such as self-policing by peers, and the elimination of architectonic configurations which allow for unsanctioned use. The suppression of the unexpected is precluded by a preference for the predictable and the controllable.

The society-wide controlled homogenization and separation resulting from the abstraction of space is manifested concretely in the architecture of everyday life. The architecturalization of separation with the goal of eliminating unknown elements is the physical manifestation of the desires to isolate and validate certain functions within a proscribed space, and expel others to designated realms. 


\section{II.i Oscar Newman and Defensible Space}

In 1973 Oscar Newman published his work Defensible Space: Crime Prevention through Urban Design which attempted to codify in architectural terms the use of exclusion in building design and planning. Newman postulated that an examination of the physical forms of the buildings which make up residential communities offers a means of explaining criminal activity in those areas - that is, that buildings themselves hold within them the ability to promote criminal activity on their premises. Newman further states that the physical forms of buildings themselves are the key to dissuading further unwanted activity (Newman, Creating 4).

Newman's work responded to concerns in the United States over rising incidences of criminality associated with a building typology new to post-war America, the large urban housing complex. These complexes are attempted manifestations of principles for communal living associated with the Modernist movement, whereby residences were vertically stacked so as to minimize the footprint of built constructions on the ground. The increased density of human inhabitation on these parcels of land allowed for surroundings areas, Modernist thinkers held, to be open for communal, un-programmed usage (Frampton 155). 
Newman believes that the emphasis on communal and public spaces in these developments results in a socialized anonymity among residents. Those who dwell within the complexes are unable to distinguish between other residents and "outsiders": non-residents who find themselves within the complexes' perimeters. A lack of consensus amongst the estranged residents hinders their ability to develop as a group an accord as to what is acceptable behaviour in these spaces. This also means that is is difficult for residents to feel or exert any proprietary feelings, resulting in the minimizing of one's personal stake in the upkeep and maintenance of the building, as well as a lack of desire to ensure the overall well-being of the building and its resident community. (Newman, Defensible 48). The Modernist housing complex, in Newman's estimation, is too public to function as a safe place of residence (Figs. 2 and 3).

Responding to these concerns, Newman's Defensible Space principles articulate building design methods which focus on the identification and reinforcement of territory delineation. Newman's studies designates spaces as falling under one of two categories; territories which building residents may "claim" as their own, and territories occupied by non-residents (referred in this discussion as "Others" to illustrate their standing as being outside of the resident community). Two of the "areas of discussion" surrounding Defensible Space identified by
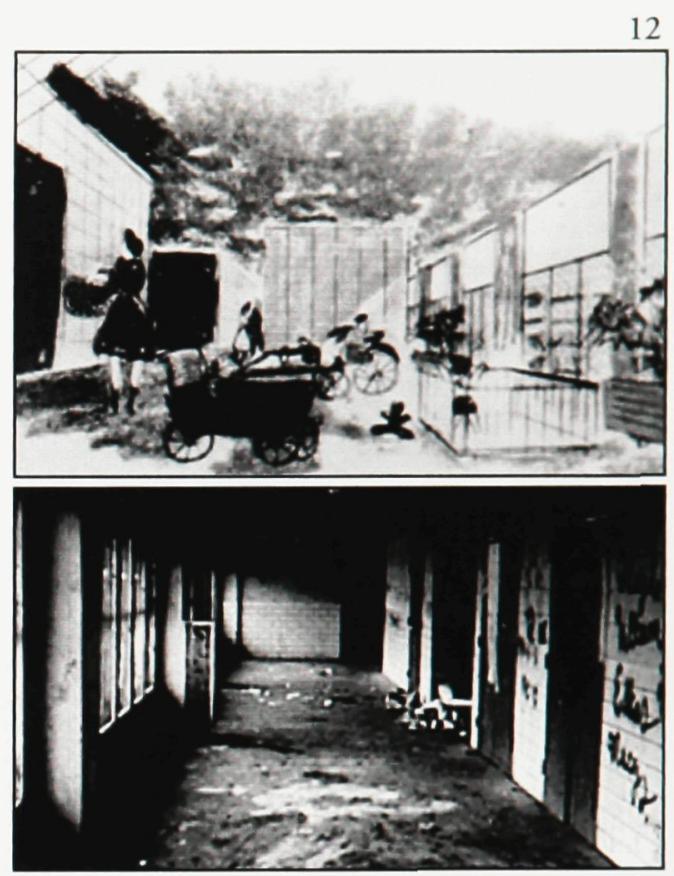

Figs. 2. and 3. Interior communal space of the Pruitt-Igoe housing complex. Conceptual image (above) and the reality, shortly prior to demolition (below). (Newman, Creating 11).

Newman cited the Pruitt-Igoe housing complex, built in 1956 and initially viewed as a new paradigm for communal living, as an example of flawed Modernist concepts. After years of vandalism and disrepair, the building was demolished in 1972 .

Newman are as follows: 
1 Territoriality : the capacity of the physical environment to create perceived zones of territorial influence (Newman, Defensible 50)

Residents must be able to claim ownership over public space surrounding their private dwellings (public space which these Other figures have access to) in order to question the actions which occur there. The influence of the resident, then, must extend beyond the private space of the residential unit and into the surrounding public space, implying ownership of the space. Implicit in the notion of property ownership is the ability to regulate those actions which transpire within it - with violence, if necessary. (Blomley 122). Newman proposes that the perimeter of the residential and surrounding public territory be articulated with physical barriers to convey that one is passing from a space in which one's presence is not questioned to a space where one must justify one's presence there (Newman, Defensible 53).

Newman repositions empty, un-programmed space as being inherently dangerous as it allows for its appropriation by dubious and potentially dangerous actors (Blomley 124). To ensure their well-being, residents must impose restrictions on the types of actions permitted within the space (Figs. 4 and 5).
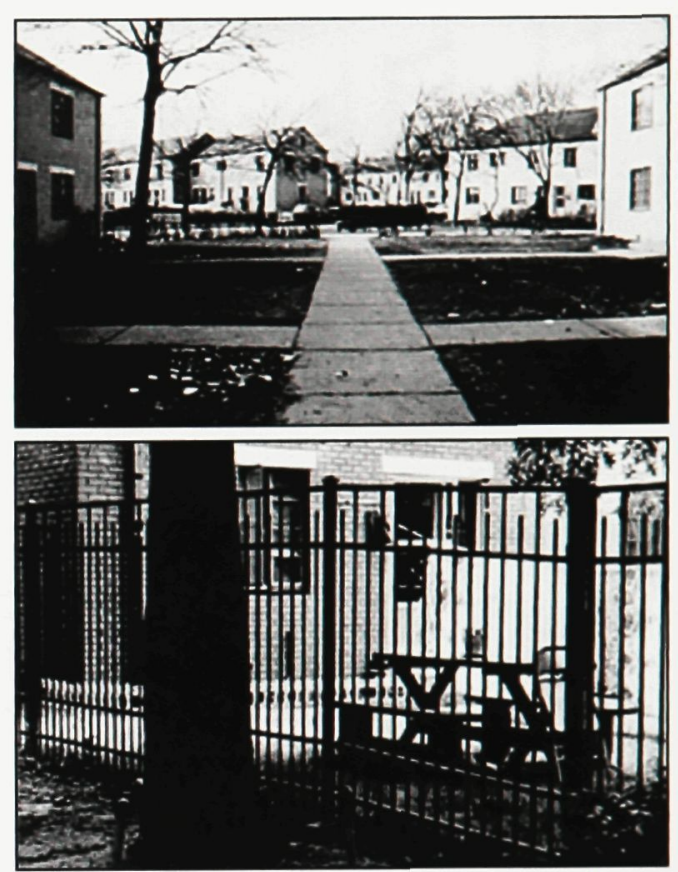

Figs. 4. and 5. Exterior space at the Clarson Point housing project, NYC. Prior to Newman's intervention (above) and after (below). (Newman, Creating 69).

Commissioned in 1969 to resolve fears of criminal behaviour on communal property at the Clarson Point housing project, Newman moved to significantly reduce publicly-accessible space. Gates and other hard barriers subdivided formerly communal space into parcels now solely accessible to individual housing units. 
2 Natural Surveillance : the capacity of physical design to provide surveillance opportunities for residents and their agents (Newman, Defensible 50)

A second principle of Defensible Space states that observation by residents is necessary to establish territorial divisions. Constant observation supports the extension of ownership by allowing for the easy identification of those who enter into these controlled areas, be they members of the community or those from outside of it (Newman, Defensible 78). The ability to identify and characterize something as 'not belonging' within public space is means of effecting a sense of ownership and control over the space. These public and semi-public spaces, supposedly open and available to all, effectively become owned and controlled by a specific group (Fig. 6).

Defensible Space principles call for a reduction of circuitous routes (found often in the housing complexes he criticized) in favour of building plans which provide unimpeded sightlines and spaces of high visibility. Clearly organized and ritualized movement is used to identify those unfamiliar with the habits of the residents (Newman, Defensible 82). Hidden spaces and

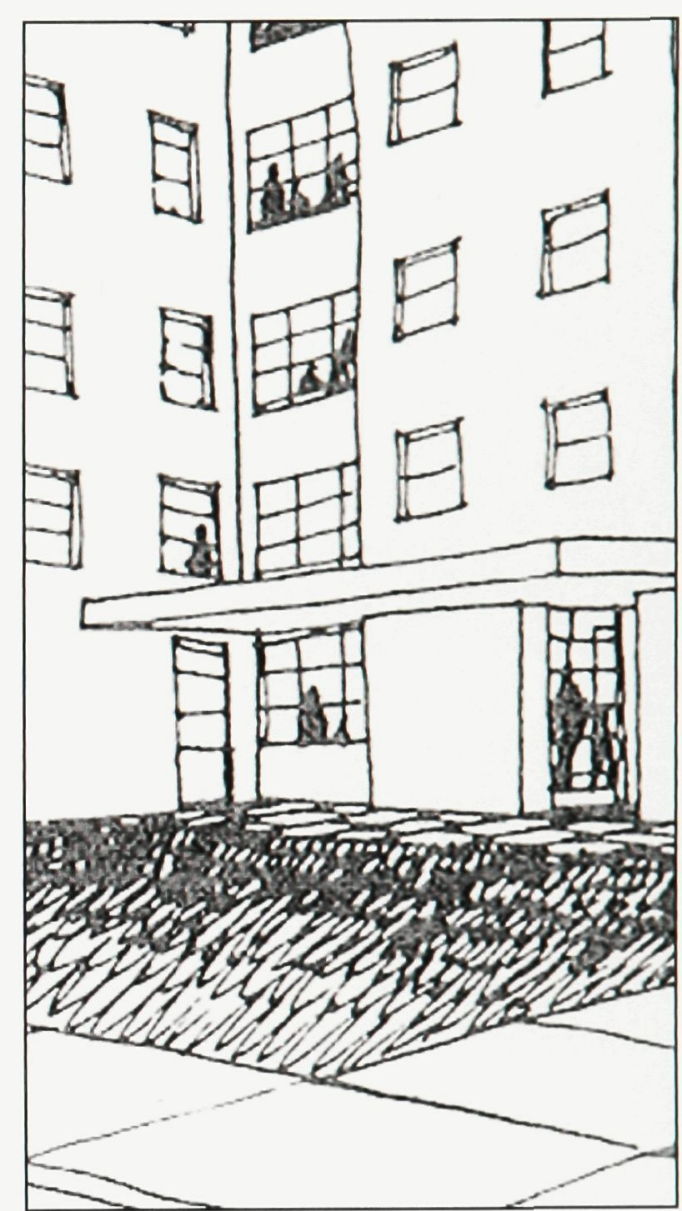

Fig. 6. Sketch illustrating the incorporation of surveillance into design. (Newman, Defensible 54).

Common spaces overlooking exterior public grounds allow for increased surveillance by the building occupants. ambiguous routes (multiple possible routes for a single destination, for example) are spaces where unwanted elements can exist undetected and unchallenged. 
Newman creates a design template which offers a form of societal control not unlike that explored by Michel Foucault in his 1975 work Discipline and Punish. In his analysis of Jeremy Bentham's "Panopticon" Foucault identifies a system of observation and control which he proposes has come to form modern society's main regulatory mechanism. Pioneering a new method of incarceration, the Panopticon forced one to censure and regulate one's own actions in a space policed by an overseeing, yet unseen, authority. Given that one does not have the ability to see this authority, it is unknown whether or not the authority is actually present - the potential, however, to be caught running afoul of this authority causes the individual to either align their actions with the desires of the authority, or expel himself/herself from the area of the authority's control. As Foucault states, it is a self-policing artifice where "all the mechanisms of power... are disposed around the abnormal individual to brand him and to alter him" (Lewis et al. 3). Foucault further astutely notes that the Panopticon differed from the previous method of jailing a prisoner in a dark, hidden cell; it was now full lighting and supervision which enabled regulation and discipline (Lewis et al. 4). As Figure 6 illustrates, Newman was cognizant of visibility's ability to identify and exclude. 
Newman's Defensible Space, in its quest to homogenize and normalize the use of space, imposes specific uses upon it. Architecturalizing the qualities of abstract spaces as identified in the previous section, Defensible Space seeks to repress difference and conflict by expulsion (Deutsche 77). Focault identifies "heterotopias", or areas of exclusion, which are created on the periphery of abstract spaces to accommodate those who have been banished from their elite centres (Foucault 4). Similarly, Newman acknowledges that a favourable by-product of his propositions is the displacement of unwanted elements to regions outside of his study areas

(Newman, Defensible 206).

\section{III.ii Mike Davis and the Heterotopia of Los Angeles}

Oscar Newman directed his explorations towards the residential sphere, albeit one which found itself within a larger urban context. Architect and theorist Charles Jencks, however, in his essay "Hetero-Architecture for the Heteropolis", identified Newman's Defensible Space theories as being influential to a trend of broader "defensible" architecture and urban developments in Los Angeles which proffered exclusion as a guiding design principle (Jencks, Hetero-Architecture 218). 
Los Angeles is so labelled "Heterotopia" because of its status as a city of minorities - it has the largest and most diverse population of any municipality anywhere in the United States, as well as the second-largest number of foreign born citizens of any American major city (Jencks,

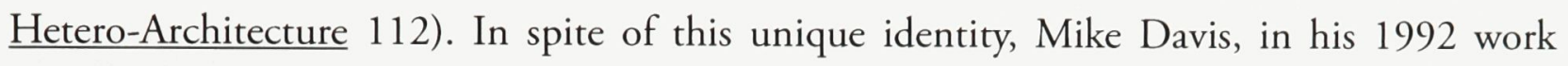
City of Quartz : Excavating the Future in Los Angeles, identifies a specific repressive intent in development strategies of the city which corroborates Jencks' assessment.

In his work Davis depicts Los Angeles as a city polarised by difference, where the wealthy reside in elite neighbourhoods and the less fortunate are segregated to "barrios" and ghettos. Spaces of interaction between the many factions in the city are limited by the segregation of public spaces which are made inaccessible to lower-income populations. The blame for this marginalisation, Davis claims, rests on municipal policy which is subservient to middle-class demands for increased spatial and social isolation. Through the privatization of public spaces and amenities, the Other, the undesired element, is disallowed access to areas where different groups may have formerly had the abilities to interact (Fig. 7). In a statement referencing Los Angeles' move towards the privatization of public space Davis states:

The contemporary (urban) "renaissance” renders ... heterogeneity virtually impossible. structures in Los Angeles, according to Mike Davis. (Wight).

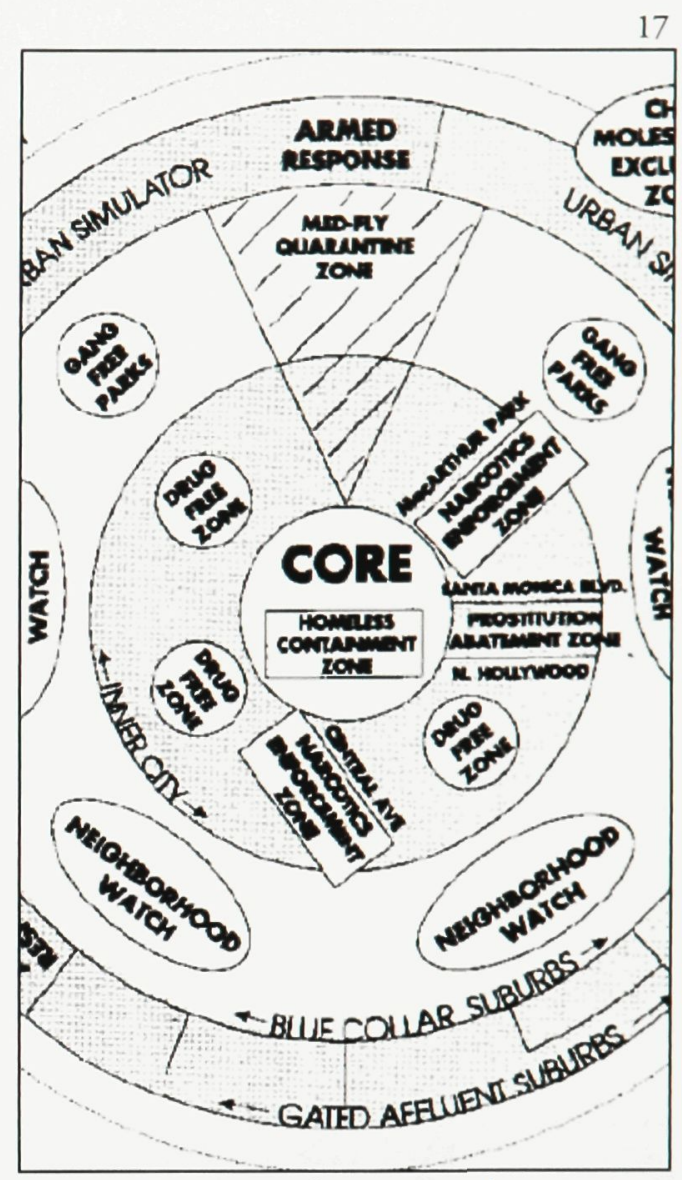

Fig. 7. Diagram of power and segregation 
It is intended not to "kill the street" ... but to "kill the crowd," to eliminate that democratic mixture that Olmsted ${ }^{4}$ believed was America's antidote to European class polarization (Davis, "Fortress").

The appropriation of public space (and the ability to exclude that this grants) is then used as a technique to eliminate those elements which are seen to compromise the well-being of certain groups. One such example that Davis notes is that Los Angeles has fewer public washroom facilities than any other major American city. Access is limited through the placement of the facilities in areas where their access may be monitored and regulated. Thus "public" washroom facilities are rendered "quasi-public" by virtue of being placed within restaurants, art galleries and private businesses, and are only accessible to paying customers - others, such as the homeless (who are often dependent upon such facilities for their well-being), are excluded (Davis, "Fortress").

Further segregation is effected through the separation of circulation routes, as exemplified by the Broadway Springs Centre in downtown Los Angeles (Wight). The office-like exterior disguises its primary function, that of a parking garage (Fig. 8). Its purposes extend beyond the simple act of providing a space to park one's car - it offers itself as a public space which

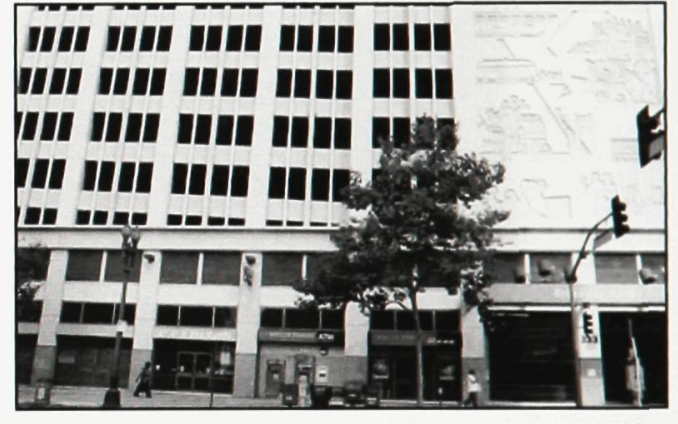

Fig. 8. Broadway Springs Centre, Los Angeles (Wight).

\footnotetext{
4 Davis refers to Frederick Olmsted, landscape architect and one of the designers of New York City's Central Park.
} 
limits its users to those with the funds to afford an automobile, and consequently entrance to

the space. Containing manicured walkways, atrium spaces and food vendors, it replaces the public spaces of the exterior where users may be forced into an undesired encounter with the Other. Entrances to adjacent buildings from the parking garage further ensure the segregation of the users from the rest of the population outside the controlled environment of the building (Wight). 


\section{HOUSING THE FLUX OF CIVIL SOCIETY}

The previous two sections examines a trend which reduces what may be termed truly public spaces (where all people, regardless of differences between them, may congregate) to be replaced by spaces which offer the appearance of being public, but in reality are only accessible to certain segments of the population. Elements which have the potential to allow for unpredictable and unsanctioned appropriations of space are eliminated in favour of elements which proffer control and predictability. The appearance of civic peace and consensus which these spaces offer are granted as the benefits of repressive and normative intents (Lefebvre 358).

The following section argues for an alternative to a public sphere which excludes. This will be offered as a reflection of changing societal needs and public mores regarding conceptions of community. Alternative proposals will focus around the acknowledgement of flux in the public sphere. Flux embodies the qualities which have been targeted in the discussion of the previous two chapters; it is that which is unpredictable, that which accepts multiple and unforeseen 
definitions instead of one which is singular and all-encompassing, that which temporarily appropriates - that which exists outside of control.

\section{III.i Public Space and the Institutionalization of Conflict}

Rosalyn Deutsche engages the implications of the identification and exclusion of groups from the public sphere in her 1996 work Evictions : Art and Spatial Politics. According to Deutsche, the Other plays a necessary role in the formation of public space, as she defines such space as implying the "institutionalization of conflict" (Deutsche 274). This is rooted in her formulation of democracy, which she posits exists when "certainty" is eliminated from the foundations of social life. The loss of absolute values, values which were thought to exist a priori, requires that consensus be reached through contact and discussion with the Other - no democratic society, then, can exist without the participation of all its constituent parts. Public space, the sphere of this discussion, is thus equated with democratic space (Deutsche 272).

For Deutsche, debate and discussion comes when fundamental assumptions are questioned in open dialogue. A space which allows for this type of debate, she continues, is one in which is constantly being redefined to suit the needs of those occupying it (Deutsche 273). A public space loses its function as a forum for truly open (and thus democratic) debate when it is 
appropriated by state authority which imbues the space with a fixed, unchanging purpose or programme. The use of the space is no longer defined by the changing needs of the people within the space, but by an authority which comes from "without" (Deutsche 275). Democratic power, Deutsche states, is demonstrated in the conflict that arises from the re-definition of "proper" usages of space in the face of the desires of the controlling power".

For the members of the Situationist International, the French politico-cultural organization formally active between 1957 and 1972, this constant spatial redefinition was the means with which one questioned the inflexible definition of the public sphere established by "the Spectacle". This Spectacle was what, in their opinion, defined public life - it was a continual ingestion of media-driven images which pacified and conditioned the population into accepting defined social roles. These roles assisted in the perpetuation of capitalist enterprises which both created and catered to the specific needs of each group, leading in turn to the atomization of the population and the alienation of individuals (Gardiner 107). Through the acts of the détournement and the dérive, techniques developed by the Situationists, one could combat the dominating and controlling effects of this constant bombardment of images and achieve a creative, authentic existence outside of the imperatives of an accumulation-based existence.

\footnotetext{
${ }^{5}$ Deutsche cites a prolonged debate regarding the occupation of a public park by homeless individuals as an example of such a conflict. Jackson Park in New York City is situated in a neighbourhood occupied by residents both wealthy and poor. At the behest of a community group a fence was erected around the park which allowed for the park to be closed and locked at night, thereby ensuring that homeless residents would be unable to sleep there. Debate over this action centered on the definition of who constitutes a 'proper' user of the public park - by ensuring that individuals without shelter would perhaps be forced to leave the community due to the loss of one of their 'residences', the 'public' that was deemed the 'proper' user was clearly limited to the 'housed' segment of the neighbourhood population (Deutsche 277).
} 
These techniques act as means of re-framing one's existing surroundings in a new light

which questions the uses and order of spaces as determined by larger power structures. The détournement actively uses existing cultural and textural materials for ideological criticisms. These materials are reconstituted so that they can no longer function as tools of a consumptive society but as avenues for free play and creativity, as well as discussion. These détournements take many forms across many different media, and often occur in venues that allow for high visibility and dispersion amongst the population - advertisements and billboards, for example, often serve as venues for détournments ${ }^{6}$. Events such as Kensington Market's Pedestrian Sundays (which prohibits, on a weekly basis, the use of automobiles on the streets of the Toronto, Ontario neighbourhood) spatialize the concepts of the détournement through the action of opening up civic spaces beyond their proscribed use and allowing for alternative uses by local community residents and organizations ("Pedestrian"). These events offer a critique of the current urban framework (ie. the amount of space in urban neighbourhoods that is dedicated solely to vehicular use) by creating an environment where an alternative living experience is allowed to prosper through a re-utilization and appropriation of that framework (ie. pedestrian congregation on formerly car-specific streets) ("Reclaim"). This critique often prioritizes the local and its specificities (for example, the selling of goods produced by local vendors) over larger fields (such as, in this case, the broader national and international interests dedicated to

\footnotetext{
${ }^{6}$ Organizations such as Adbusters frequently display their take on re-conceptualized advertisements ("Spoof").
} 
the construction, shipping and maintenance of automobiles and their roads). By these means the act of catering to uniquely local needs and peculiarities becomes a challenge to some of the fundamental organizational precepts of the environment ${ }^{7}$.

The Homeless Vehicle Project (1988) developed by installation artist Krystof Wodiczko offers a similar attempt at re-conceptualizing the "proper" usages of public space. The work consists of multi-purpose vehicles designed to meet the needs of the urban homeless. Little bigger than shopping carts and placed on wheels for mobility, these vehicles provide a place to collect cans (as a source of income and sustenance), store personal possessions, and seek shelter (Deutsche 172) (Fig. 9).

Offering a critique of the forced exclusion of the homeless from the public sphere, the work re-conceives public squares and streets as places of domesticity where homeless individuals can temporarily appropriate a space to create a home. Tension arises from the superimposition of what is, for the average housed city dweller, the most intimate of environments (the home) and the quintessential space of communal public living (the public square). Upturning expectations as to what actions may be considered acceptable in this environment, the viewer of the Project is made aware, through the work's presence, of how much is in fact prohibited in this supposedly

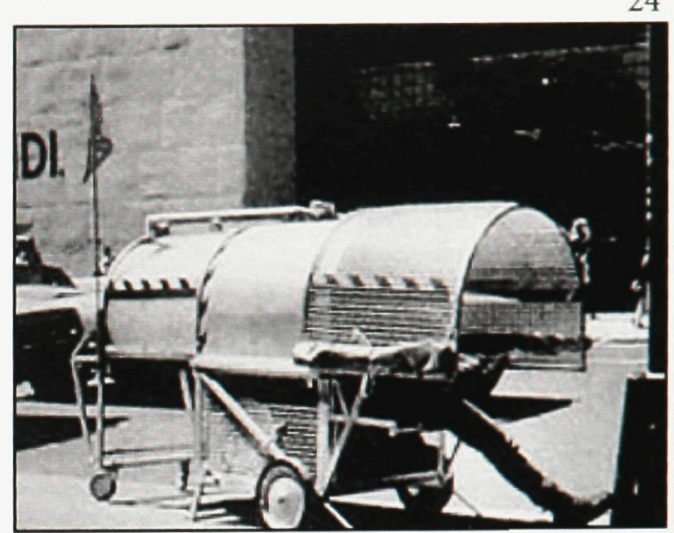

Fig. 9. An installation of Krystof Wodiczko's Homeless Vehicle Project ("Krzysztof").

\footnotetext{
${ }^{7}$ The approach of the Situationists is not dissimilar the method of using 'tactics' examined contemporary French theorist Michel DeCerteau. 'Nonproducers of culture' (i.e. the general populace) use 'tactics' to counter the controlling forces of society (similar to the Situationists' Spectacle) by attributing unexpected meanings to items produced by these forces (i.e. mass-produced items). These errant practices are small, temporal, dispersed, and escape study by the controlling system. Given that one uses the resources and vocabularies of the elites that have been imposed upon them, DeCerteu identifies the transformative actions of tactics as inherently containing political critique, leading to a political meaning in everyday life. The purchasing of a t-shirt at a store and the subsequent alteration via tears in the fabric and the insertion of pins is the example of a 'tactic' (Gardiner 168-170).
} 
"public" area of free expression.

The ability of the Vehicle to accommodate many of the functions one needs to survive on the streets (protection, income, etc.) acknowledges a lifestyle dependent upon the appropriation of the specificities of the immediate surroundings to function. The presence of other people who may be solicited for cash, the presence of architectonic elements which provide shelter and protection from the elements, the ability to quickly leave an area should one's presence attract unwanted attention and perhaps punishment - all these are elements which are affected through one's "lived" experience in a particular space, and which make the appropriation of a space a unique venture whenever and wherever it may be.

\section{III.ii Building Flux}

The spatialization of the critical arguments demonstrated in the previous examples implies a role for architecture within this discussion - both as an armature which supports the rigorous maintenance of the status quo through the exclusion of unwanted elements, as well as a venue for the questioning of said foundations. While more a critique of the profession of planning than of architectonic principles, Lefebvre offers an interesting take on the role architecture plays in the support or resistance of fixed-readings and status-quo-maintenance. 
His investigation takes the form of a comparison of two iconic and dichotomous urban forms found, he claims, in many South American countries; the planned city of large-scale buildings and regulated growth and the barrios residing on the periphery of many of the larger cities. For Lefebvre, the "shanty towns", the products of appropriation and spontaneity (both in reference to their planning and the construction of the actual constitutive units which, in the absence of expensive construction methods, must respond to the immediate surroundings and are often constructed from found materials) offer a "social life (which is) far more intense" than the the city districts, which may be constructed in the singular enactment of an urban plan (Lefebvre 373). The communities of the urban plan consist of units which have little intimate connection to the immediate environment (due to the repetition necessary to the enactment of a large-scale scheme), are unable to accommodate future unforeseen functions, and are closed to the potential of future manipulation. They are the antithesis of the constantly changing, temporary and unique structures found in lower-class communities (Figs. 10 and 11). The ominous fate Lefebvre predicts for such communities is an eventual inability to contain the unplanned elements within the controlled communities, which, now unable to absorb or push to the edges its troublesome elements, is threatened with potentially violent dissolution ${ }^{8}$ (Lefebvre 374).
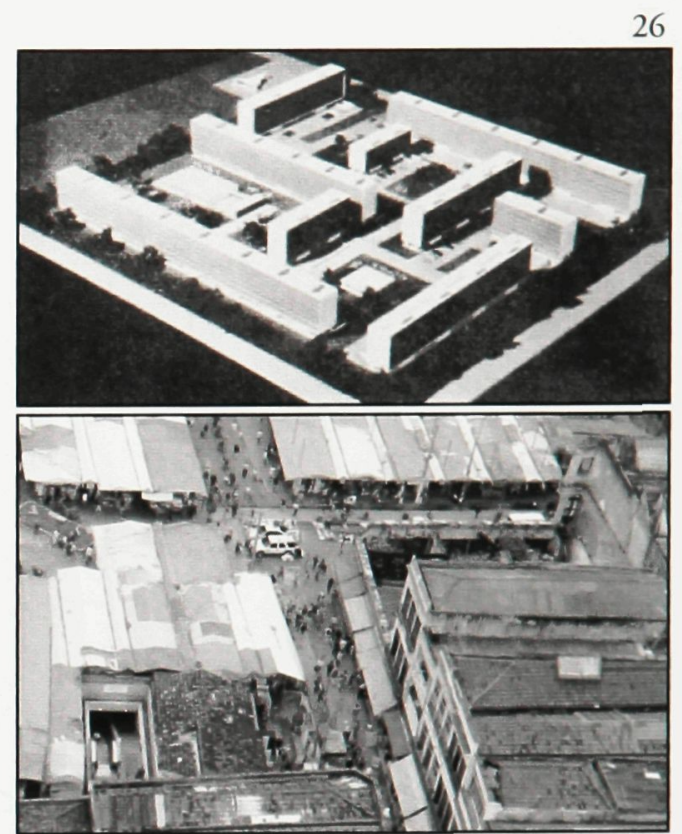

Figs. 10 and 11. A model of a "superblock" communal residence found in the planned city of Brasilia (above) ("The Superblock), and a photograph of a barrio located on the periphery of the city (below) (Pindorama).

\footnotetext{
${ }^{8}$ It is useful here to consider Lefebvre's discussion of "Differential Space" in The Production of Space which expands his thinking on eventual dissolution of societies organized according to the principles of Abstract space. The segregation of spaces and functions that are required for the smooth operation of consumerist enterprises which fuel abstract space allow for conflict to arise due to the inability of spaces to receive unexpected functions and appropriations. The constant expulsion of elements which challenge the sanctioned operations of the spaces mean that conflict is always present, and this continual presence threatens to permanent undermine the control of any overseeing power. When the segregating forces are eventually whittled away, the Differential Space of constant discussion and continual redefinition arises (Lefebvre 352).
} 
The fractures that existed within the societal landscape of Los Angeles California were blown

wide open in 1992 in the form of violent riots. The reason for the riots, as identified by Charles Jencks, is segregation founded on a mentality of excessive self-definition by difference (Jencks, Heteropolis 93). Jencks has been previously referenced in this paper with regards to his description of Los Angeles as a "Heterotopia", a term relating to the lack of an ethnic majority in the Angelino population, the great disparity in wealth amongst its many occupants, and the relatively independent functioning of the neighbourhood enclaves that have resulted from these differences.

In his book Heteropolis : Los Angeles, the Riots and the Strange Beauty of Hetero-Architecture (1993) Jencks identifies a unifying ideology driving the work of the so-called "LA School" of architects $^{9}$ which seeks to respond to the multifarious nature of the city and its residents. Terming the approach to design "en-formality" (that is, planned informality), Jencks attempts to refute the signifiers of separation, closure and inwardness which, in his estimation, both respond to and encourage the divisiveness which eventually fuelled the riots ${ }^{10}$. Defensive Newman-inspired "wallified" architecture which turns its back to surrounding conditions through the complete internalization of its programmatic elements; the rough edges and exploded volumes of enformal architecture are influenced by the flux which surrounds them, seeking the unexpected

\footnotetext{
${ }^{9}$ Jencks identifies architects Charles Moore, Frank Gehry, Morphosis, Frank Israel and Eric Owen Moss as constituting the first tier of the LA School. Other architects associated with this 'school' include Craig Hodgetts, Michele Saee and Brian Murphy (Jencks, "Hetero-Architecture" 220).

${ }^{10}$ Jencks groups such works under the umbrella term 'mono-architecture'. Mono-architecture is defined as being mono-functional, clearly expressed so as to avoid any ambiguity in understanding its function/structure/layout etc., and able to completely satisfy the needs of its users so as to avoid working in conjunction with surrounding environments/buildings. The work of Mies van der Rohe, Minimalism, most classicisms and most corporate building are all proffered as examples of mono-architecture (Jencks, Heteropolis 75).
} 
latent in confrontations which opposing voices (Jencks, "The LA Style" 4). The banal and

mundane of the industrial age's man-made "second nature" is re-conceptualized as fodder for new and unexpected experimentation (Jencks, Heteropolis 59).

Jencks identifies in the LA School the desire for ambiguity and the subversion of expectations. Materials collide in unexpected fashions - the work of Frank Gehry is particularly masterful in this respect, as materials such as chain-link fencing lose their formerly banal and defensive connotations and gain new interpretations through light and welcoming gestures (Figure 12). The collision of primary forms defies attempts to 'read' the functions of the building through observation at a distance (a subversion of the clarity of functions expressed as virtue in Modernist works), prompting exploration and direct experience as a necessary means to understanding the building (Jencks, "The LA Style" 3).

The mono-functional building of traditional Modernist paradigms is turned on its head as practitioners of en-formality carve, mould and combine programmatic elements to give a sense of unexpected encounter and promote an openness to foreign experiences. Jencks identifies particularly in the work of Gehry, Eric Owen Moss and Frank Israel a desire to deconstruct and display formerly internalized functions. Jencks attributes initial investigations in fragmentation 
to Gehry, citing his 1976 design for the Jung Institute which breaks the building into a series of smaller pavilions, skewed so as to heighten the differences between them (Jencks, Heteropolis 59). Warehouse renovations by Eric Owen Moss and Frank Israel are offered as further examples of this deconstruction, as the office typology is blown apart and then reconstructed as an interior village. Underneath the warehouse roof warped volumes containing individual programmatic elements collide against one another, creating an interior "urban" fabric of labyrinthine and abstracted "streets" and "squares" whose organizing principles are hidden away in the confusion (Jencks, Heteropolis 63) (Fig. 13). The inclusion of non-traditional elements such as leisure facilities and home furnishings indicate a further attempt to eschew the paradigm of the office as solely a place to work (Jencks, Heteropolis 66).

LA-based architect Thom Mayne of the firm Morphosis identifies the fractured and ambiguous forms of his work as responding to the estrangement engendered by the rise of individualized and technologically-enhanced communities which rely less and less on face-to-face communication for establishing personal relationships. In his essay "Connected Isolation" Mayne states that this redefinition of community has led to existential confusion over one's role in public life. Mayne sees a reactionary force then placing an increased value upon privacy and autonomy leading to the questioning of whether a "public", a cohesive and decision making body, can

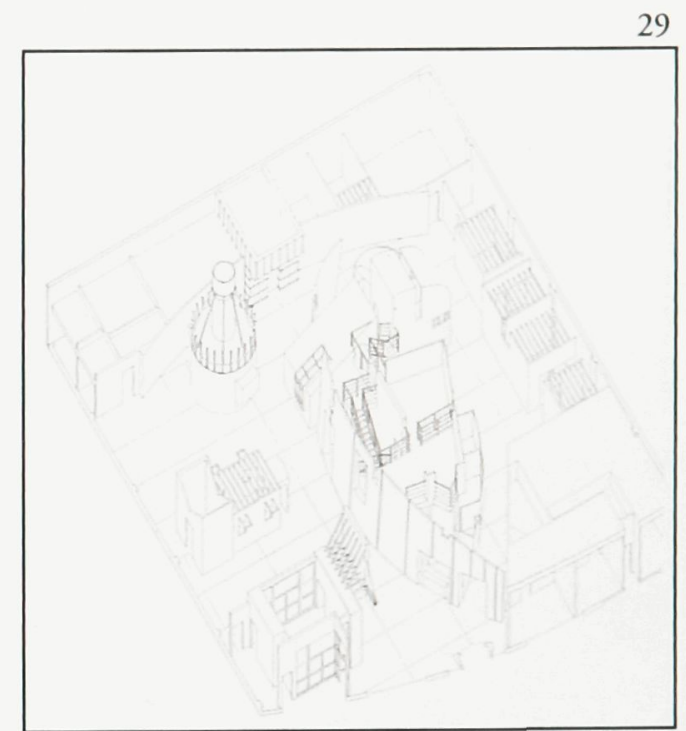

Fig. 13. Propaganda Films Studio, designed by

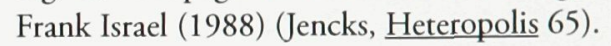

\section{9}


exist (Mayne, Connected 9).

Urban and cultural critic Walter Benjamin identifies the crowded metropolis as a place of isolation, where both psychological and physical barriers are built around the individual in order to counter the fear of being lost in the crowd (Vidler, Warped 67). Rather than reinforcing boundaries between shifting interpersonal and societal relationships, Mayne's built work attempts to break them down. Relationships no longer respect traditional territorial and temporal restraints, and the city, as armature for these communities, cannot be defined by its borders and edges (Mayne, Connected 8). The permanence of localities is undermined, and thus buildings must assume a more dynamic and adaptive state to satisfy the shifting needs of its users.

The role of architecture in this society is to physically manifest this fracturing through the repositing of the relationship between building users, boundaries, and program. Mayne posits that the built form must consist of concrete and stable elements acting as frameworks of order and continuity (paradigmatic values in Modernist building design), which then in turn act as armatures for acts of differentiation and variability (Mayne, Connected 13). Boundaries may be implied beyond the proper building site by utilizing elements of the landscape, different 
programmes may be treated as layers which may be overlaid on top of one another to eliminate

hierarchical standings between the elements, and edges may be blown open to allow apparently illicit access (Mayne, $\underline{\text { Connected } 15) . ~}$

The resulting cacophony is no longer meant to be legible from a single point of visual comprehension - through the dispersal of building elements over a given site and subsequent hyper-articulation of the isolated pieces, Mayne hopes for coherency to come from an understanding of a series of fragments. As demonstrated in Morphosis' 1990 Crawford Residence, one comprehends the building through the act of journey, giving the building legibility a temporal dimension (Fig. 14) (Mayne, "Crawford”).

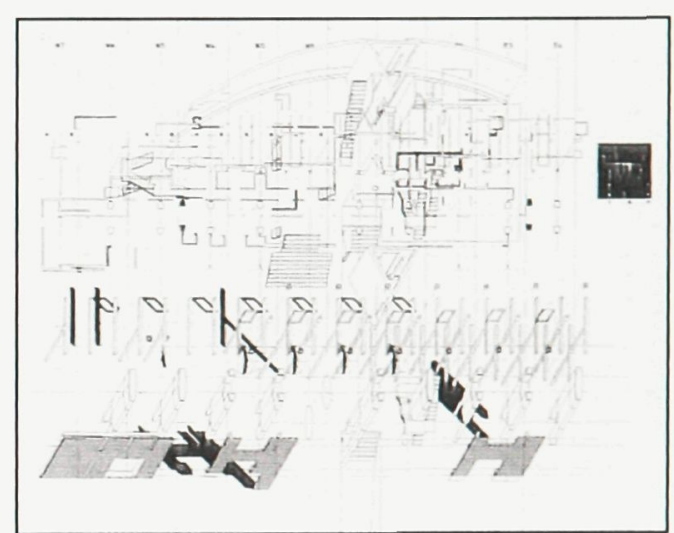

Fig. 14. Crawford Residence, designed by Morphosis (1990) (Mayne, Morphosis II.20). 


\section{CASE STUDIES}

Beginning with a discussion on segregation, exclusion and control, the focus of the document shifted to a discussion of the role of ambiguity and unretricted freedom in society and space. A shift in scale accompagnies this course. Initial discussion centered on the application of the mechanisms of abstraction to a generalized societal whole; it then focussed in on the segregation of specific groups and actions performed within the whole. Disscussion eventually led to a focus on an architecture of individual experience, where the acknowledgement of flux provoked exploration and unpredictable responses.

While the discussion of the following case studies does not follow as explicitly linear a path, the studies referenced all share qualities which make them relevant to the investigation at hand. Three of the projects are seats of governance (two municipal and one federal) and one is a shopping mall. They are all institutions which have intense relationships with individuals and the public body at large. The government institutions are charged with meeting the needs of 
their constituents and must be deemed accessible by the public. The mall is a centre of public

life of a type commonly found in urban centres worldwide, as well as a commercial institution whose professed purpose is to cater to consumers' needs and desires, and as such it posits itself as an inviting public environment.

The acknowledgement of the needs of the individual is measured with the needs of the institutions to maintain their authority and unhindered operation. Despite the unity and control they wish to project, these institutions are all beholden, in varying degrees, to the actions of individual actors, and as such to elements of flux. The case studies examine the way in which the works put forth in this section address this relationship. 
IV.i Former Ottawa City Hall : Building as Monument to Civic Ideals

\section{Ottawa, Ontario, Canada}

The former City Hall of Ottawa, Canada (architect John Bland; occupied between 19582001), was designed in the International Modern style. The use of the International Style for monumental public architecture was a dominant trend in Canada between 1950-80. The postwar period saw a transformation in the appearance of cities as architects and clients turned away from the classicisms of the moderne style, now perceived as being retrograde (Glassford 2). The city hall, as a symbolic representation of the values of the community, was vested with new progressive ideals that the International Modern style embodied ${ }^{11}$. A desire for clarity of expression through functionality and rational planning was tied to the greater role which municipal and provincial governments played in the lives of citizens, taking responsibility for many new community services (Glassford 11).

These and other new administrative roles led to city halls dedicating more spaces to offices. The Ottawa City Hall reflects this in its explicit representation of the three functions of civic governance of the period - legislative, administrative and public service. Following the Modernist ethos, best exemplified in Le Corbusier's 1927 plan for the League of Nations in

\footnotetext{
11 Alongside the Ottawa City Hall, other major Canadian cities saw the building of city halls in the Modernist style during the post-war period, such as Winnipeg, Toronto, Edmonton, and Hamilton (Glassford 18).
} 
Geneva, the building is not expressed as a single monolithic mass but a collection of volumes specific to the particular functions which they house. These volumes are arranged so as to best express their particular use, to maximize functionality, and to convey symbolic values deemed to be reflective of a civic structure representing the needs of a population (Fig. 15). Depicting both efficiency and clarity of form and function, the City Hall acts as a representation of the institution of civic governance in its purest form.

Intending to display the accessibility of the municipal government to the residents of Ottawa, the building fronts onto a public plaza, a paradigmatic gesture found in Modernist city halls. The ground floor of the structure is enclosed entirely by glass and acts as a public reception area, with a front desk and gallery space. Entry to this space passes beneath the council chambers, representing the legislative aspect of the building and expressed as an orthogonal volume jutting from the otherwise flat façade (Fig. 16). A large circular staircase leading from the ground floor to the chambers reception area on the second, making explicit the ideal that the legislative branch of the government is readily accessible to the public. The prominent placement of the council chambers with respect to the square, as well as its placement over the entrance to the building proper, is meant to convey this as well. Manifest in other Modernist Canadian City Halls such as Edmonton and Toronto, the council chambers, as a representation of the

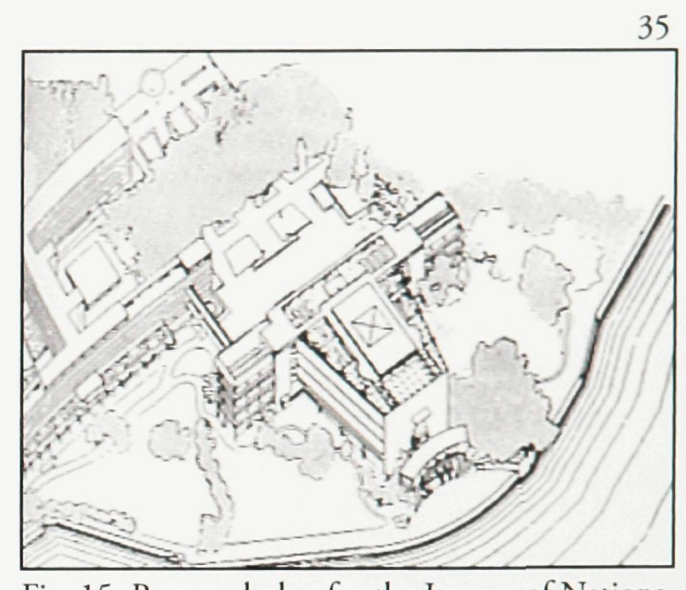

Fig. 15. Proposed plan for the League of Nations, Geneva, by Le Corbusier (1927) (Frampton 159). 
executive branch whose rulings directly affect the constituents, is pushed front and center so that its importance is immediately grasped. The 'administrative' portion of the building is represented as a larger rectangular mass from which the chambers protrude. It is articulated in a regular manner so as to reflect the regular, repetitive, and 'background' tasks which make up the daily workings of municipal administration (Fig. 17).

The building is designed to offer an easily legible yet abstracted representation of the workings of municipal government. This 'readability' through its articulated volumes and emphasis on public accessibility (via its placement off of a public square and the emphasis on depicting public areas and routes through the building) displays a desire by the architects that this reading be made to the constituents, those who are to be directly affected by the decisions made by the institution the building houses. This legibility through its symbolic representation allows it to take on a monumental form as well, as it comes to represent the beliefs and ideals of the larger community. Its location on an island, removed from the center of civic life in downtown Ottawa, positions the building as a rarefied object which, despite its symbolic approachability and legibility, one must seek out with the specific intent of visiting it. It stands to represent the best aspirations of Ottawa's citizens and the life of the civic community, yet it finds itself far removed from both. 


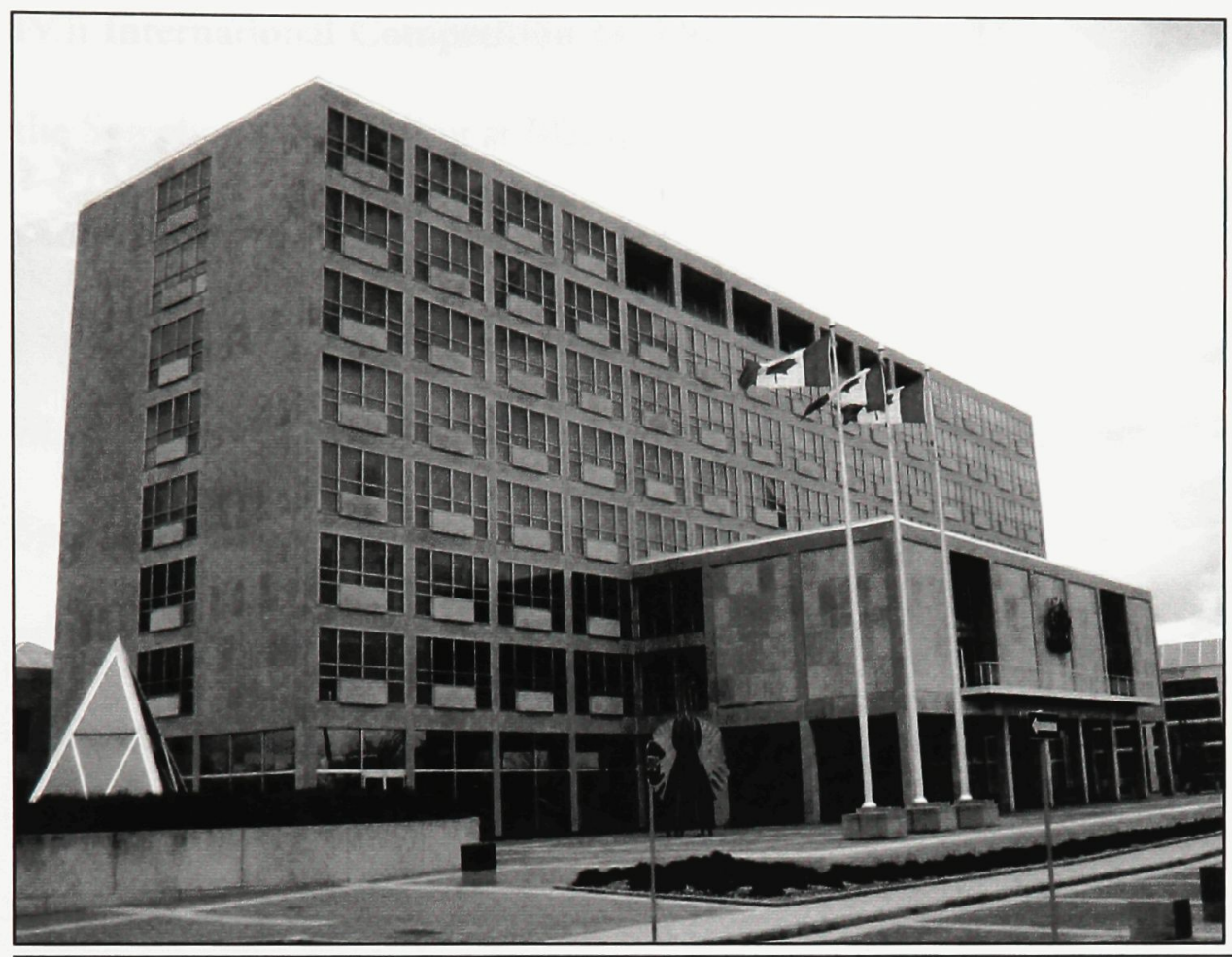

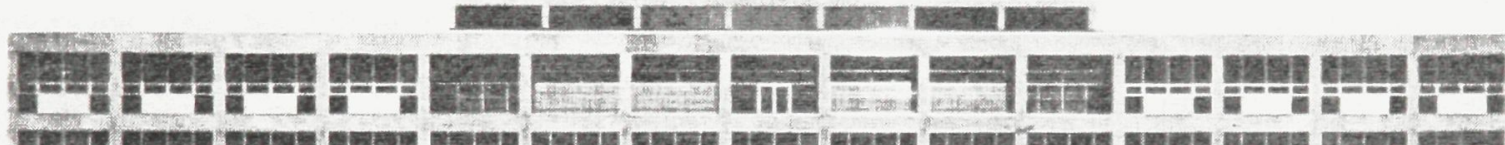

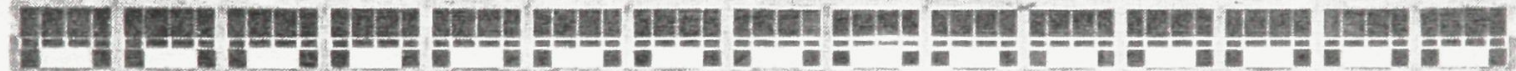
$19 \mathrm{c}$ 1. 5 1 1. 2 T)

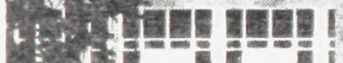

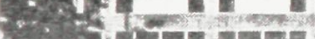
$+2+2+2=-3$

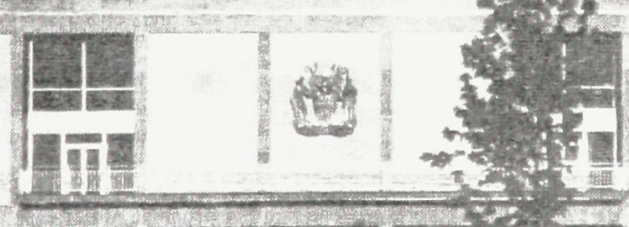

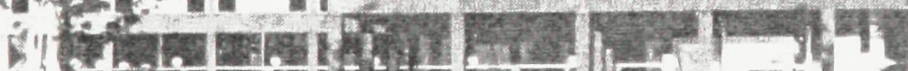

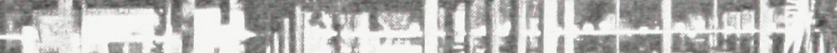
M.
Fig 16. Former Ottawa City Hall, designed by John Bland 1958

The Council Chambers juts out prominently over the Plaza.

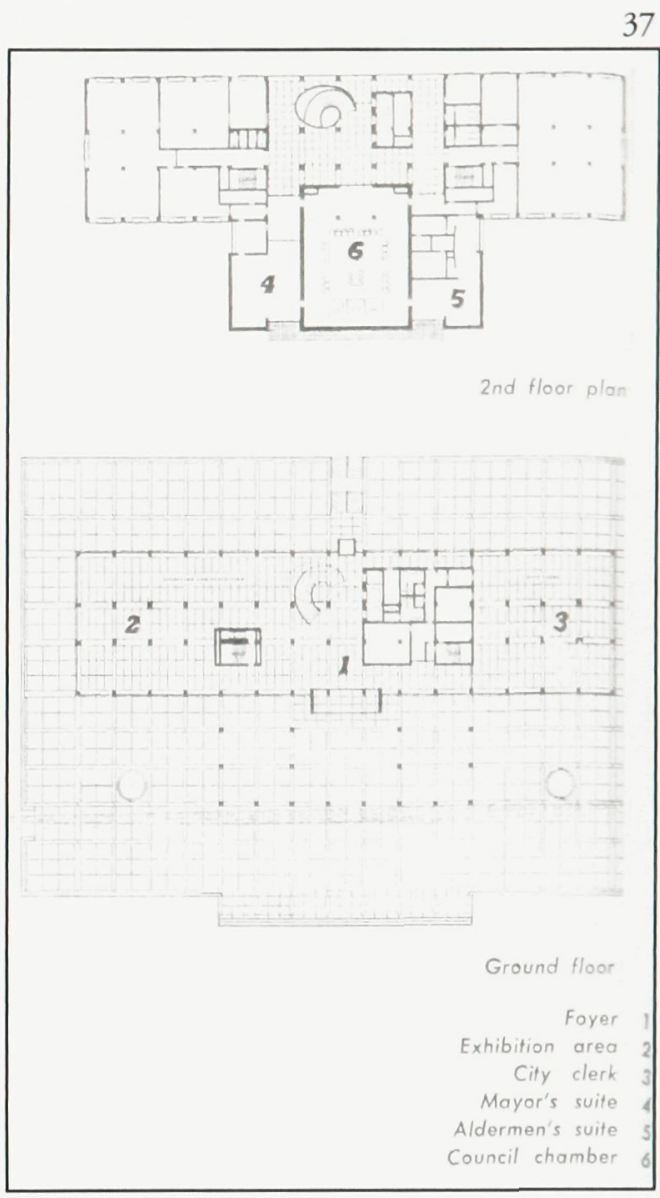

Fig. 18. Floor Plans, Former Ottawa City Hall (“Criticism" 34, 36).
Fig. 17. Facade, Former Ottawa City Hall ("Criticism" 39). 
IV.ii International Competition for Urban Design Ideas for the Parliamentary Quarters in

the Spreebogen : Building as Manifestation of Civic Realities

Berlin, Germany

Morphosis' 1992 competition entry for the Berlin Parliamentary District Master Plan in Spreebogen offers an interesting counterpoint to the former Ottawa City Hall. Both projects address the place of monumentality in the housing of institutions of governance, as well as contemporary understandings of the relationship between the institution and the people it governs. Whereas the former Ottawa City Hall tries to render the institution accessible and legible through its articulation of volumes and immediate comprehension of their roles and connections, the Spreebogen plan intends to display a civic presence by intertwining itself with the existing site conditions and embedding itself into the pre-existing fabric of circulation systems, buildings and open spaces.

The firm explains this approach as an investigation into the nature of government. Morphosis questions representations of government as monolithic and static (Richter 76). These depictions of governance have traditionally used ceremonial public squares, rigidly symmetric buildings and revered objects to project an image of civic/national unity. This unity is meant to be as 
singular and foundational as the buildings themselves, unquestionable in their interpretation

(Mayne, Morphosis II.1). The firm contends that this singular view of the state, however, is no longer an able representative of its diverse constituents, and thus must gain the qualities of flux and fluidity, allowing it to be open and transformable (Vidler, Warped 214). As opposed to the static and geometrically "pure" form of the former Ottawa City Hall, the Spreebogen complex is decentralised and, according to the architects, able to re-define itself to accommodate the needs of its surroundings. As the complexity of civic and national identities eschew simple ordering devices, the hierarchy of functions and roles as established by traditional formal

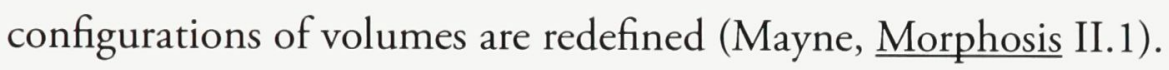

This complex and shifting identity is expressed through a proposed integration into the existing civic fabric as opposed to a single isolated site. The building takes as edge conditions the river, markets and other civic conditions that have contributed to the urban life on the site and attempts to act as a connective tissue between them, almost as if to 'augment' or call to attention their significance to the area (Richter 76). Landscape elements, urban infrastructure, and building elements are integrated into this urban system. The building forms, eschewing monolithic and monumental volumes in favour of long, intertwining braids, are loosely organized so that public circulation may pass through them; by allowing and promoting this 
transgression of boundaries (potentially a frequent occurrence due to the complex's proposed

location in the heart of the civic life of the area) the architects hoped to defy notions of fixity and closure, which theoretically allows for growth and change to accommodate new needs (Richter 76) (Figure 19). 


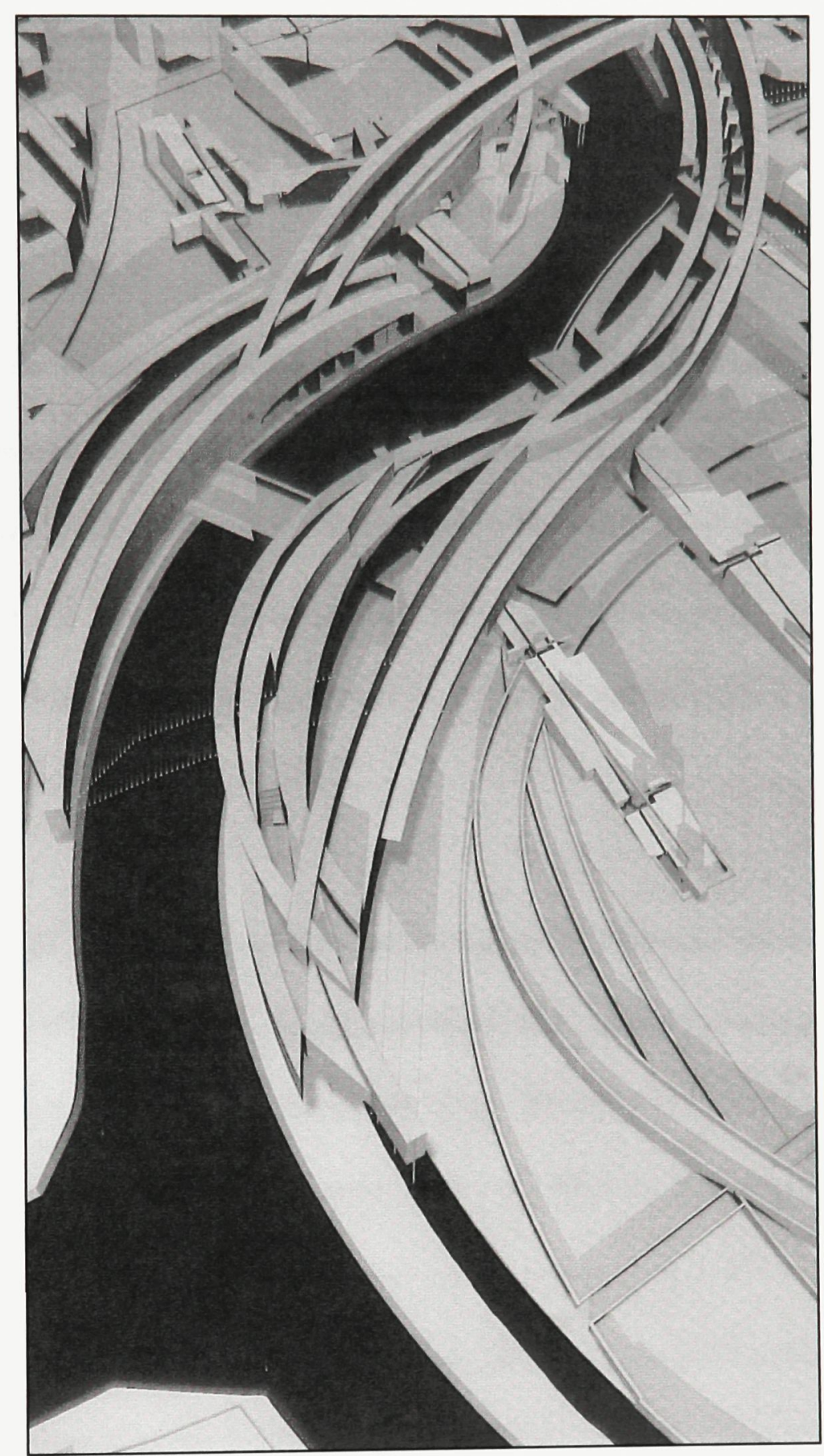

Fig. 19. Perspective, Proposal for the Berlin Parliamentary District Master Plan, Morphosis (1992) (Mayne, Morphosis 7). 
IV.iii Nathan Philips Square and City Hall : Building as Conflict between Civic Ideals and

\section{Civic Realities I}

\section{Toronto, Ontario, Canada}

While Nathan Philips Square and the adjoining Toronto City Hall (opened in 1965) offer more formal similarities to the former Ottawa City Hall than the radical re-imagining of the government structures at Spreebogen, the location of the Square and City Hall in the urban core of the city offers a measure of the urban integration that Morphoses deems to be so important to the functioning of civic institutions. The intersection of this integration and the building's monumental status are the focus of this case study.

Nathan Philips Square exists as one of the busiest outdoor public spaces in Toronto's urban centre. While acting as a large urban plaza, it is still clearly associated with the monumental Modernist City Hall ${ }^{12}$, acting as a forecourt for the institution (Figs. 20 and 21). Elevated walkways which delineate the boundaries of the square assist in clearly defining it as being under the auspices of the City Hall's jurisdiction. This is supported by a lack of articulation and spatial complexity in the square which provide the unimpeded sightlines needed for the immediate identification of unsanctioned activity. Further vigilant observation is provided by
12 The avant-garde Modernist scheme for the Toronto City Hall building, conceived by Finnish architect Vilo Revell, was selected over a more conservative scheme during the course of an international design competition. As with the Ottawa City Hall building, the desire was to build a structure which would represent the progressive civic ideals of a new age. The building offers a somewhat more expressive take on the volume-articulationrepresenting-functions design principal used at the Ottawa City Hall, but the elements are similar. The ground floor is dedicated to public service and opens directly onto the plaza, the council chamber sits above this level and is displayed prominently to the occupants of the square (who are invited to walk directly up to the level where the chamber sits via publicly-accessible elevated walkways which touch down at various points in the square), and the administrative functions of the building are housed in two thin curved slabs which are offered as expressive backdrops ("Toronto"). 
the municipal employees and other users who take advantage of the square's location in the downtown business and shopping district.

Despite these safeguards against unsanctioned appropriation, an unauthorized claim was staked on the space of Nathan Philips Square. Utilizing the large canopy and vents located by the entrance to City Hall, homeless people began creating encampments in the square (Fig. 22). Ironically, many of the aforementioned safeguards against intrusion appealed to the homeless users; knowing that they were in a space of high visibility, the homeless felt far more protected from the violence that they would more likely be exposed to in the marginalised spaces to which they are traditionally relegated in the city (Sewell). This high visibility also dissuaded the authorities from using any overt displays of force to remove the squatters, as their prominent siting prompted debate on the plight and rights of the homeless, in which many took the side of the squatters.

The presence of the squatters in this public sphere questioned the rule of the authority and its ability to govern, as well as its claim of representing the civic values of inclusiveness and equal representation. The power of City Hall was openly contested not only by those who simply sought a place where they were safe from harm, but also those who debated the responsibility 
of the authority to address an issue which had previously gone unacknowledged. Despite

a January 2005 City Council ruling extending a bylaw to prohibit people from sleeping in the Square, the issues the unauthorized encampments raised still engender debate in the city (Sewell). 


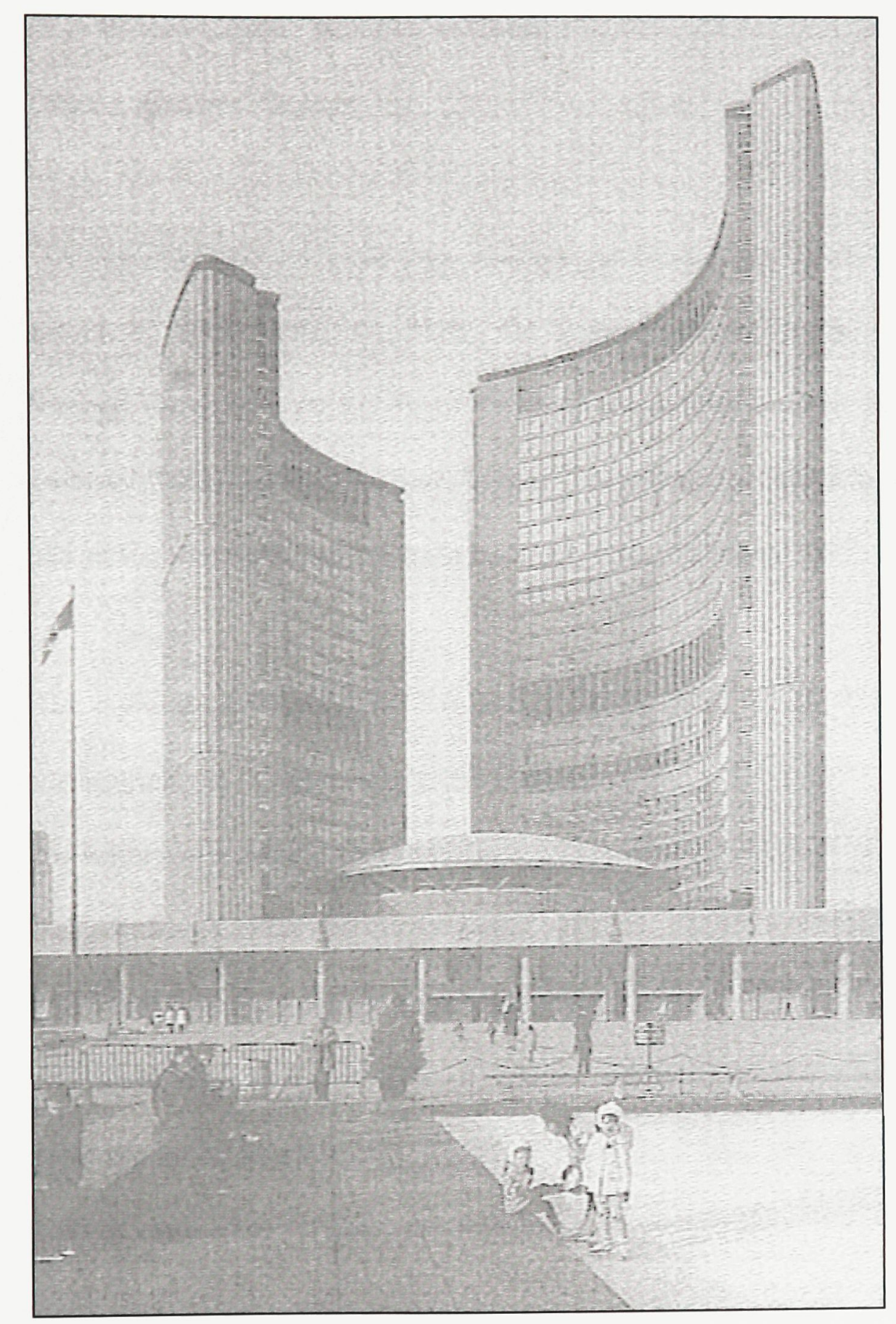

Fig. 20. Plan, Nathan Philips Square and Toronto City Hall. Highlights by the author. Viljo Revell (1965) (Glassford 50).

1- Location of catwalk bordering the perimeter of the Square.

2- Location of City Hall's canopy which faces the Square.

Fig. 21. Nathan Philips Square with the Toronto City Hall in the background. Viljo Revell (1965) (Glassford 49).

Fig. 22. Homeless occupying space under the canopies of Toronto City Hall (Sewell).
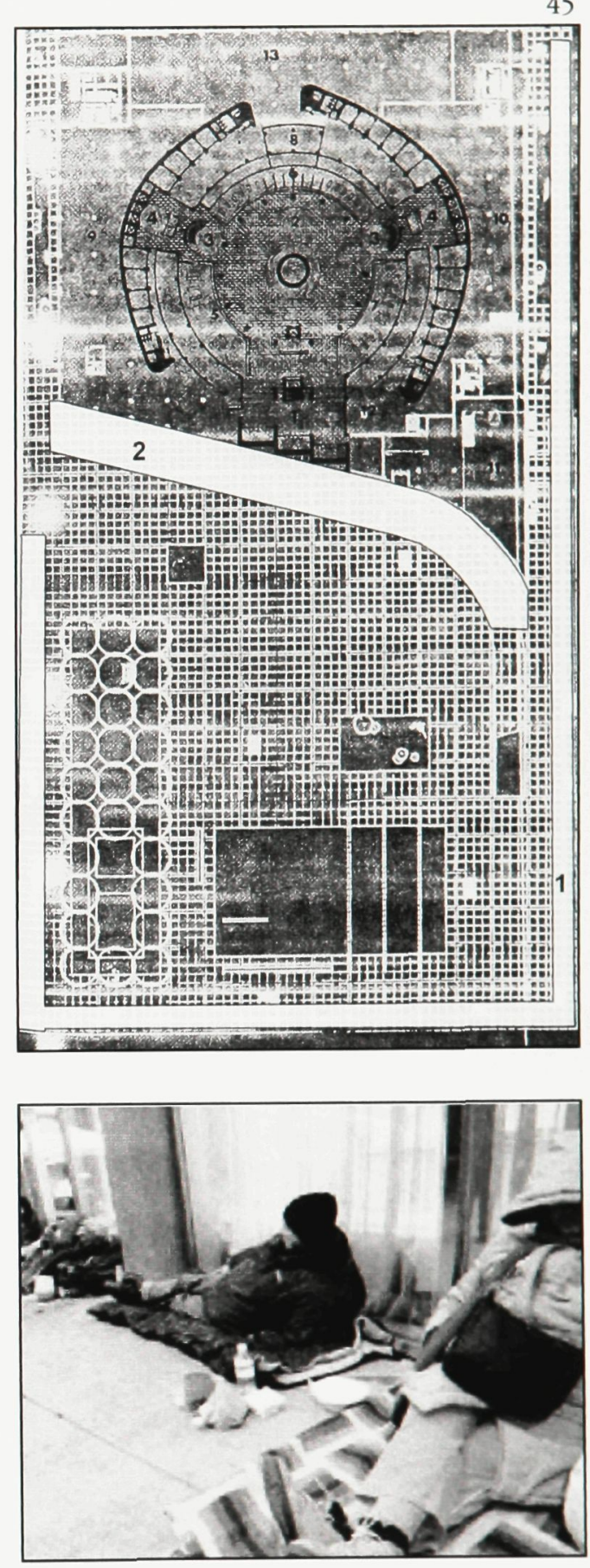
IV.iv Rideau Centre : Building as Conflict between Civic Ideals and Civic Realities II

Ottawa, Ontario, Canada

The contemporary urban interior mall has positioned itself as one of the paradigmatic public spaces in North American cities. The typology evolved from the desires of its inventor, Victor Gruen, who sought in the 1950s to re-establish a center for personal interaction and communitarian spirit based upon face-to-face interaction which he felt was in danger of being lost in the development of post-war urban America (Dovey 126).

The position of the Rideau Center as a center of urban life in Ottawa's downtown core is undisputed. Its construction in 1981 was met with claims that it would destroy the vibrant street life and eclectic mix of stores and vendors that existed along Rideau Street. After it was built, Rideau Center did not destroy that mix as much as internalize re-defined version of it within a 3 floor, 171 store complex which, at over $90,000 \mathrm{~m} 2$, is the second-largest mall in the city. Despite covering multiple city blocks, the Rideau Centre manages to minimize patrons exposure to the street through the use of covered bridges, which ensures that these patrons will only be exposed to vendors approved by the mall's owners, the Viking Rideau Corporation. 
As with many covered malls, the Rideau Centre has posited itself as an interior environment with its own set of corresponding realities. The lack of uncontrolled change in the usage of its space rented to commercial ventures is but one of the ways in which the interior is kept closely monitored. As well, the very act of containing the space of the mall within an enclosed environment cut off from the effects of temperature and climatic/weather change creates the illusion of a reality distinct from the surroundings outside. Maintained by the managing authority, it is an environment where only the rules of this authority apply.

Even this controlled system, however, contains within it uncontrolled elements of chance. The proximity of the Rideau Centre to downtown business centres, municipal and national landmarks and institutions, and locales for retail and entertainment have framed the mall as an ideal central hub for the city's OC Transpo bus line. Located on the adjacent MackenzieKing Bridge at the south end of the mall, the Mackenzie-King Station serves all three of OC Transpo's principal bus routes along with all express routes and several cross-town routes ("Transitway"). The stop was also to serve as the final stop on the north-south leg of the dieselpowered O-Train prior to the project's hiatus.

Immensely popular with Rideau Centre shoppers (according to a 1996 study approximately 
60 percent of shoppers used public transit as means to reach the mall (Canada 162)) and non-

shoppers alike, the mall is flooded with thousands of transit-users everyday. Crossing through the mall to reach Rideau Street which borders its northern edge (and further destinations beyond), the mall acts as a conduit for pedestrians, many of whom have not come with any explicit desire to consume the goods being offered by proprietors of the mall. Shoppers and non-shoppers alike are granted passage through the mall, a condition which benefits the mall retailers with increased sales given the forced route past retailers that commuters must take (Fig. 23).

This access often displays its potential to allow for unsanctioned activities to occur within the mall. This most often occurs on Friday and Saturday nights after the mall's stores close (9:00 p.m. and 6:00 p.m. respectively), as the mall corridors remain open until 1 a.m. to accommodate the transit users' movement through the building. The radically changed character of the mall due to this programmatic inversion (as while it is still an environment for wandering, occupants are hampered in their ability to browse and consume goods) is highlighted by the new character of actions that animate the building.

While the presence of mall-employed security personnel and video cameras may be implicitly 
felt by those occupying the mall during regular shopping hours, the regulating force in the

mall is generally the gaze of the other mall users, from shoppers to store clerks ${ }^{13}$. In this sense the closed store fronts, and the reduced crowds that come with that closure, lead many afterhour occupants to act as if they have been released from an authoritarian gaze. Groups sitting on stairs, expletives loudly exclaimed down halls, and a general sense of free license displays a sense of freedom experienced by those walking in corridors where their actions were earlier more restricted (Fig. 24). An architecture where all pedestrian paths act as store-lined gauntlets is inverted when the storefronts are shuttered; one is given a sense of walking unnoticed behind the backs of authority figures.

The circuitous paths of the Rideau Centre (a common element to many modern malls which seek to maximize the time potential shoppers spend in the building) are transformed from a tool which serves commercial ends during operating hours to one that permits the playful defiance of the gestures described above. Rideau Centre, with its clipped sightlines and abruptly-turning corridors, confounds attempts by occupants to form a cognitive understanding of one's place within the complex. Just as one is unable to orient oneself to the time of day due to the lack of time-telling devices, one finds it difficult to orient oneself with respect to landmarks existing outside the enclosing walls of the mall, and thus to the larger context of the mall in the city. 
The continuous façade of shops which line the walls and the decentering effects of selected but

limited views to different levels and pathways creates a disorienting effect. But while this assists in conceiving an interior realm completely cut-off from the distracting life outside (which ultimately helps to induce the shopper to linger and consume goods), after the stores close and the mall loses its consumerist function, the warren of hallways creates the possibility for unmonitored experiences. Couples can find intimate spots to talk, skateboarding teenagers are given venues to film their stunts, friends can congregate; the ability to stake a temporary claim on a piece of territory is granted due to an architecture that permits privacy ${ }^{14}$. As such, the Rideau Centre acts not only as a pedestrian path come closing time, but a place to wander, to explore, to gather in a space implicitly under the rule of an authority, but acting as a de-facto playground.

\footnotetext{
${ }^{14}$ One may note the similarity between these acts and the "détournements" of the Situationists and the "tactics" of DeCerteu.
} 

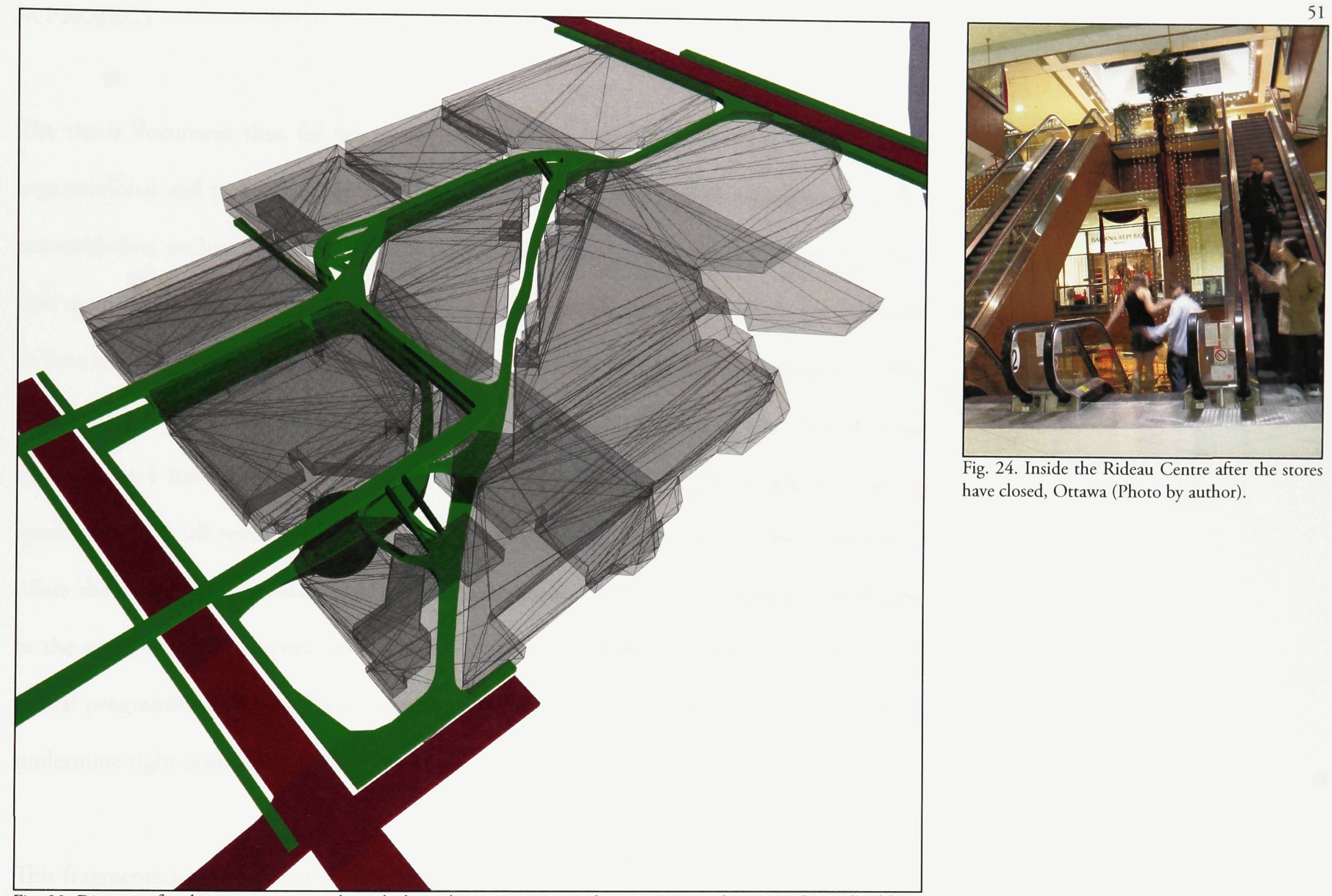

Fig. 24. Inside the Rideau Centre after the stores have closed, Ottawa (Photo by author).

Fig. 23. Diagram of pedestrian movement through the Rideau Centre. Green bars represent pedestrian paths, and red bars, vehicular paths (Rideau Street at left, Mackenzie King Bridge at right) (Image by author). 


\section{PROJECT}

The thesis document thus far has examined the use of spatial abstraction to support the organizational and controlling desires of overseeing powers. Through the mandates of capital accumulation, we have seen how this abstraction has allowed for the fragmentation of society into quantifiable units - of all aspects of society, from people to spaces - which are organized to best suit this accumulation. This fragmentation and the subsequent qualification of these fragments has led to the perceived need for an architecture which excludes. The methods of exclusion I have discussed focus around the reduction of truly public spaces - that is, spaces in which all members of the public may occupy at their leisure - for space which offers the appearance of being public. This appearance, however, hides exclusionist intents as the space is made inaccessible to unwanted segments of the population. Strictly-defined spatial programming and implicit ownership are used to dispel problematic elements which undermine tight centralized control of a space.

This fragmentation and exclusion has been criticized for a myriad of reasons explored in this essay, but a common theme amongst the aforementioned critics is that it counters fundamental precepts and desires of our society and those individuals residing within it, and that the 
continued maintenance of this system has destructive potential. Those who have manifested their criticisms architecturally have done so by introducing elements of the unpredictable and the unexpected into their works. Buildings are designed so as to allow for unexpected temporary uses. Building masses are broken apart so as to reduce their monumentality. Buildings require exploration to discover different elements, which never fully cohere into a complete structure. Materials carry banal and restrictive connotations to be re-imagined in unexpected and graceful ways. The transgression of boundaries is encouraged through careful design planning. The building itself is incomplete and ready to assume new roles.

\section{V.i Intents and Outline}

This thesis proposes that the traditional manifestation of a monumental civic institution, as represented by City Hall, does not properly address the current needs of the citizens of the city. It stands as a monument to and representation of correct governance, and thus appears beyond reproach; existing within an eternal, unchanging time frame, it sits as an object apart from the civic life it oversees.

I propose a re-imagining of Ottawa City Hall which takes into account the fluidity and integration needed to represent a society seeking to counter divisive tendencies. For an institution 
representing the individual will and voices of its constituents, the proposal is to be accessible to those who seek representation and acknowledgment of their desires and needs; as a centre of power and a symbol of communal civic spirit it must take on the role of a monument and a representation of ideals. An introduced element of flux will mediate these qualities, producing an urban institution suitable for both the individual and the municipal community.

The qualities of flux are defined as:

1 unpredictability (such as the unexpected presence of foreign actors in a space)

2 temporality, impermanence, appropriation (such as the temporary use of a space for a purpose other than that defined by its "official" program)

3 the permeability of boundaries (necessary to accommodate flux, but which also allow for formerly marginalised elements to enter into regions of interaction)

4 decentralisation and the possibility for dissemination (where no element exerts a dominance over others, and elements may spread apart without "compromising" an understanding of the whole)

My study area encompasses the region between the Current Ottawa City Hall and the northern boundary of the Rideau Centre shopping mall at Rideau Street, which contains Confederation Park, the Mackenzie-King Bridge, and central transit stops (TransitWay OC Transpo bus stops 
and a station for the proposed Light Rail line) (Fig. 25). The project incorporates certain

functions of City Hall into the existing conditions already present on the site. The project, then, calls for a significant renovations and additions to Rideau Centre and the MackenzieKing Bridge.

The project unpacks the traditional elements of the Modernist City Hall, manifest in this project by Ottawa's former City Hall located on Green Island. The Former Ottawa City Hall (hereafter referred to as the FOCH) sought to interpret the institution of City Hall as a series of individualized components efficiently acting in conjunction to create the effect of a unified institution. Similarly, the proposed New Ottawa City Hall (hereafter referred to as the NOCH) will be reduced to its component parts. Unlike the FOCH, however, these component parts are not combined in a singular structure - rather, they will be treated as individual nodes which may be spread throughout the study area (Fig. 26). The physical separation of the nodes over the large site is not meant to imply isolation, however, but rather elevate the importance of the movement, the flux, between the nodes. Monumentality is not embodied by a singular structure with internalized working components, but rather the transference of information between the components. This transference, a temporal act, is externalized, no longer contained within the structure. 
The individual nodes, as previously mentioned, are the unpacked functional components of the FOCH (Fig. 27):

- The Plazas (North (1) and South (2))

- The Legislative/Executive branch (as manifested by the Council Chambers (3) and the City Councillors Office Block (4))

- The Administrative branch (as manifested by the Municipal Employee Office Block (5))

- The Public Service branch (as manifested by the Service Centres (6))

- The Tower (7) (a later addition to the FOCH, but a typical component of many modern City Halls, including the Current Ottawa City Hall (COCH))

- The Symbolic Routes (as manifested by the Canal Pedestrian Bridge (8) and the Mackenzie-King Pedestrian Walkway (9))

- The Community Cultural Centre (as manifested by the Library (10) and the Gallery (11)) 


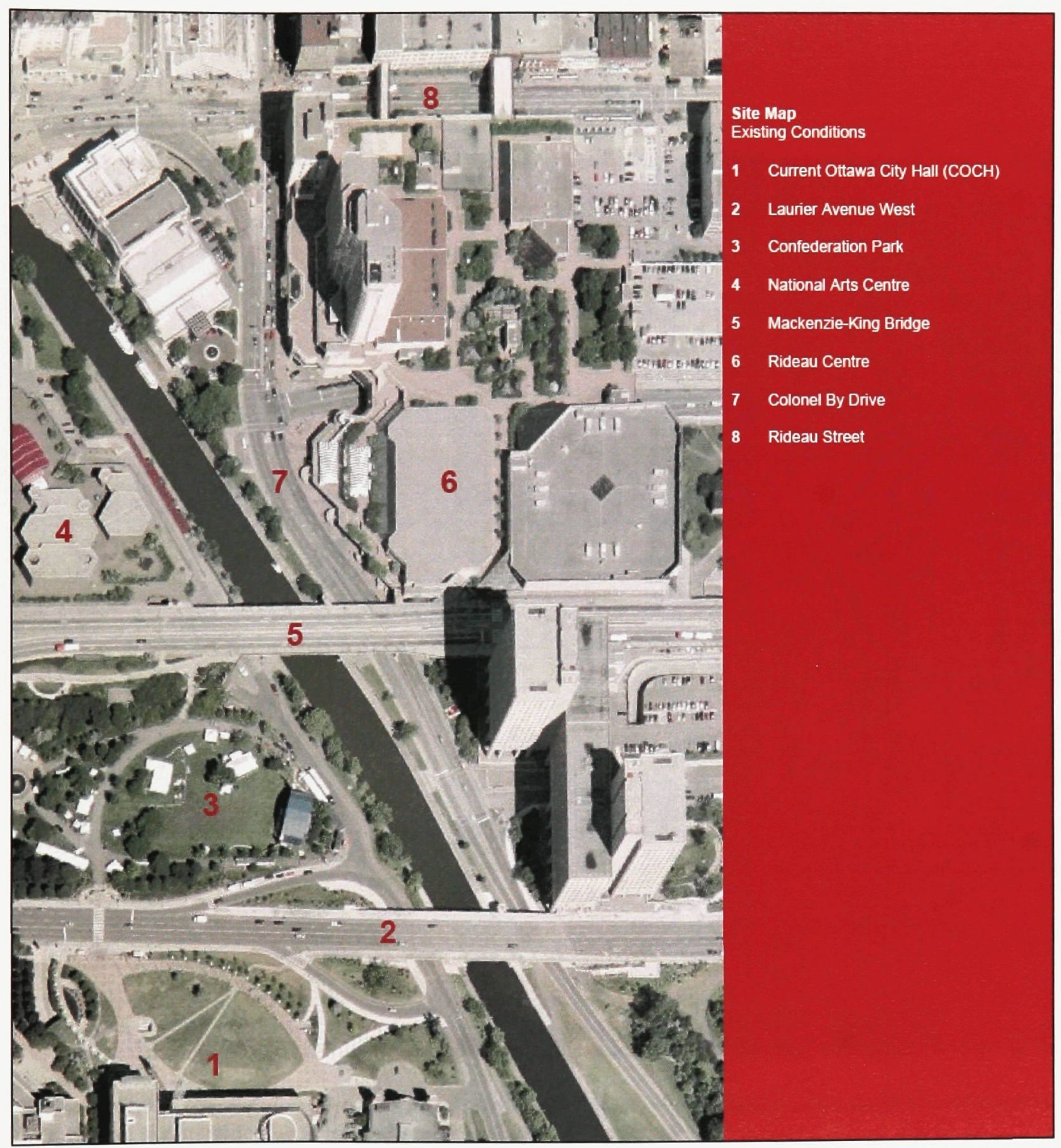




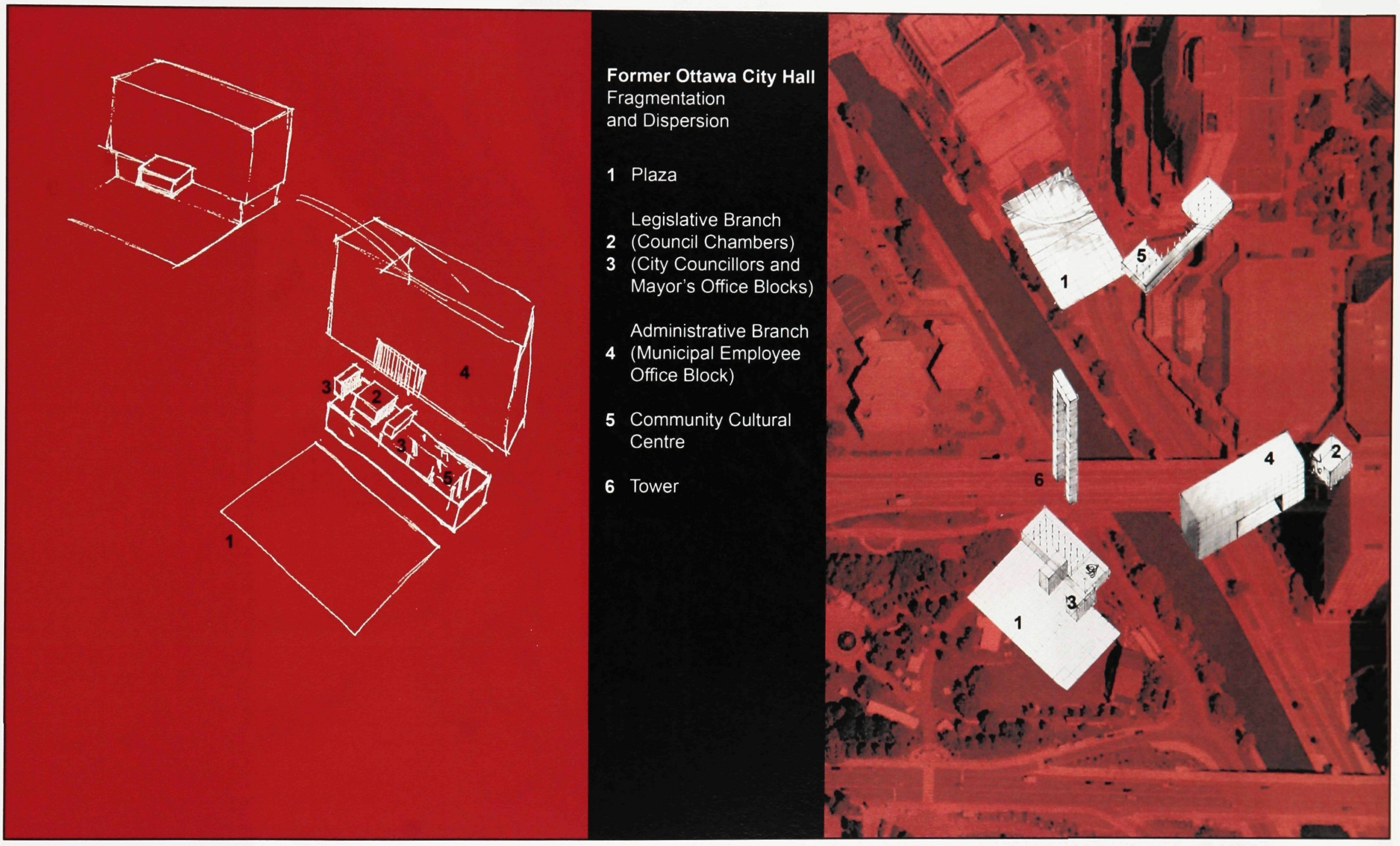

Fig. 26.

The Former Ottawa City Hall is used as a generative device. Fragmented into its constituent elements and dispersed throughout the study area, the institution is re-conceived as a set of Nodes and connections. 


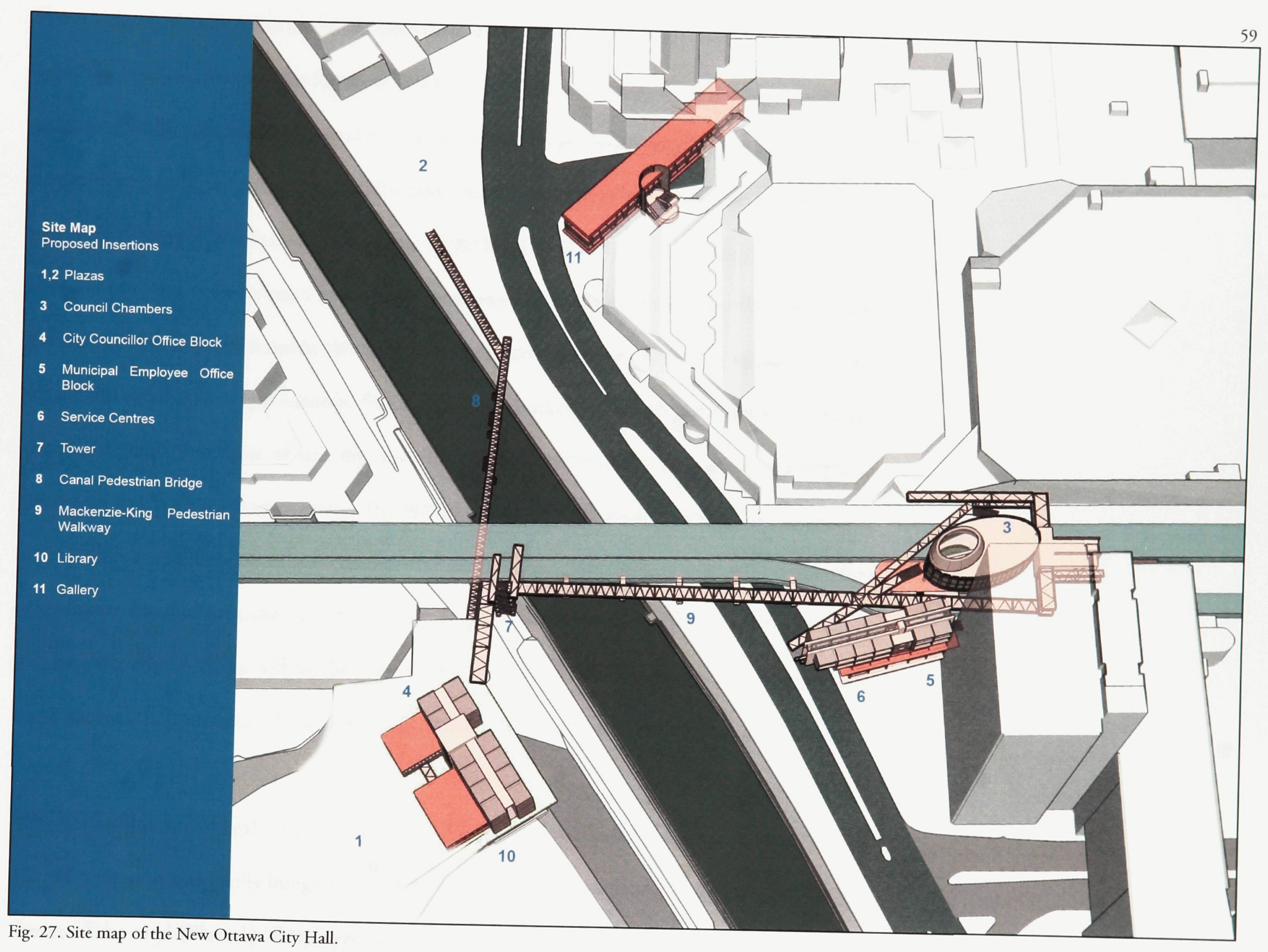


These individual nodes exist as entities unto themselves; that is they are not completely dependant upon the other nodes in order for them to function in some capacity. People may interact with them as individually functioning units, but there will always be an implication that they are a component in a functioning whole. This determination of the 'whole' is nebulous, however, as while the unit may only form of a fragment of the NOCH whole, the 'individuality' of the unit allows it to act as a whole unto itself and meet many of the needs of its users. That being said, there is an implication between the units of connectivity between the other nodes, that they are components in a larger scheme. The connective tissue is, as mentioned, the flux between the nodes, and the nature of this flux means that these connections may appear ambiguous, temporal and perhaps non-existent. The fluidity of the overall NOCH complex comes from this continual redefinition of associations and connections. The nodes are located so that they may respond to and gain alternative meanings from the local rituals and festivals. These shifting site-specific relationships will further expose the institution to temporal variations, making it exist within the lived time of the individual, rather than the eternal time of the monument.

This dispersal of nodes and the elevated importance of the relationship between them allows for the NOCH to be more fully integrated into the fabric of Ottawa's urban centre, the metaphorical 'heart of the city' (Plate 1). Employees of the municipality, individuals seeking civic services, 
and those going about their personal business in the area will all overlap and occupy the same

shifting areas (see the intersection of pedestrian and transit routes with the Council Chambers and Service Centres, as depicted in Plate 1, detail 1). The former structure which existed as an isolated object which one had to seek out, will now be experienced peripherally by a greater number of individuals; exposure to the $\mathrm{NOCH}$ will often be incidental. This regular exposure will not undermine the symbolic significance I believe a civic institution should posses. Rather, the inclusion of incidental and unexpected elements (such as an overheard bulletin regarding a mayoral announcement; the surprise encounter with a group of City Councillors on the way to a meeting along a public bridge; or the 'activation' of everyday spaces by civic uses, such as Council Meetings) will increase the significance and the accessibility of City Hall.

The connection between these units may be identified as paths, although there is no forced adherence to any particular route. Following a path will not necessarily lead to a complete understanding of all the facets of the $\mathrm{NOCH}$, as too many of its components operate on schedules independent of one another and the flux between them is ever-changing. Rather than determinations, these paths act as frameworks which allow for the potential for certain occurrences. Paths for three users are loosely defined: civilian pedestrian, municipal employee, and vehicular transit. As implied, these paths are not mutually exclusive - they are loosely 
defined and overlap. One civilian pedestrian path runs North-South across the site, from the Northern Plaza and the Gallery, across the Pedestrian Bridge, to the Tower, to the City Councillors offices and Library, and the Southern Plaza (Plate 2). The other civilian pedestrian path runs East-West, from the Southern Plaza, to the Councillors Office Block and Library, to the Mackenzie-King Pedestrian Walkway, to the Service Centre, Council Chambers and Transit Hub (Plate 3). The municipal employee / power broker path is similar to this second pedestrian path. The vehicular paths are the mass transit routes along Mackenzie-King Bridge (buses and potentially O-train); the automobile route along Colonel By Drive (a vehicular artery connecting the downtown district to areas southward); and the Canal during the summer months, which is accessible to privately-owned boats. 


\section{V.ii Nodes}

\section{The Plazas (North and South)}

Counter to the traditional relationship between the plaza and the City Hall lobby (often located closely to the Council Chambers, displaying an idealization of the intimate relationship between the public and the executive branch), the plazas are located on the periphery of the site, furthest removed from their traditional focus (encircling the Council Chambers) (Fig. 28). The widening of the gap between these two elements allows for existing urban infrastructure and other programmatic elements to be infused into the linkage that still exists between the Chambers and the Plaza. These plazas are pre-existing open spaces (Confederation Park (i.e. the South Plaza) and the area behind the Government Conference Centre (i.e. the North Plaza)). Both are highly trafficked, acting as through-spaces for pedestrians, places for relaxation and observation of the local features, and sites for congregation around the local festivals (annual music festivals, for example, are held in Confederation Park, and the other space holds installations related to the annual Winterlude celebrations). These plazas also serve as entrance/end points into the $\mathrm{NOCH}$ complex. 


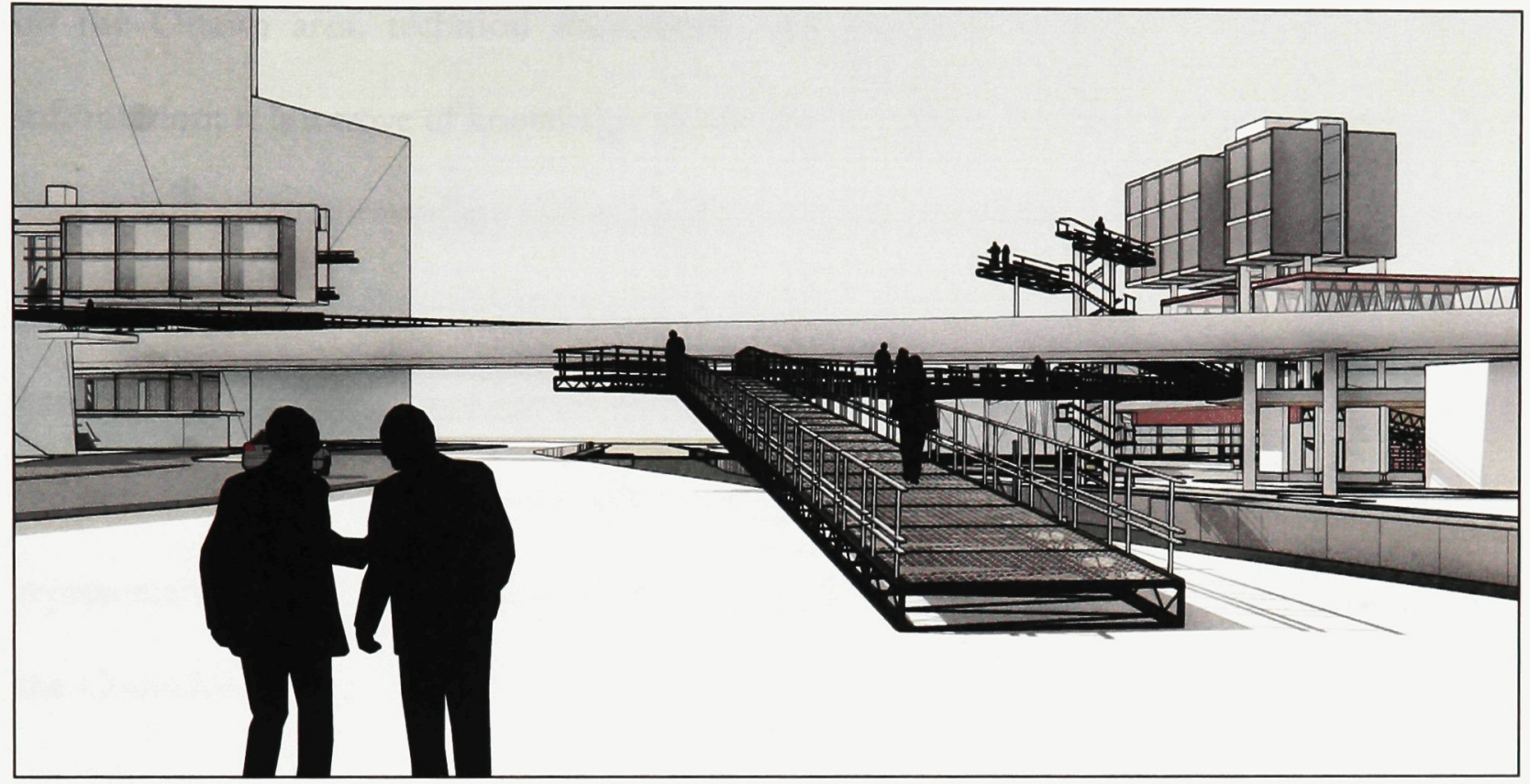

\section{The Library and Councillor's Offices}

The South Plaza slowly rises at its North Eastern tip to form a large mound. Aside from simply being a space of transit which may be passed through (directly to the north is the Tower, the western end of the Mackenzie King Pedestrian Walkway, and the southern end of the Canal Pedestrian Bridge), it is also a place to relax and sit, a place of display (say, for Winterlude sculptures), and a place to organize gatherings or audiences. People may also congregate in the plaza at the top of the mound, which grants surveys of the surrounding area (Fig. 29).

Underneath the mound is the Library, accessible to the public and containing literature
Fig. 28. Perspective, New Ottawa City Hall. North Plaza.

Looking Southwards down the Rideau Canal, with the Canal Pedestrian Bridge in the centre of the scene. The City Councillor and Municipal Employee Office Blocks may be seen in the distance.

(a) the thibrary, accessible to the public and 
on the Ottawa area, technical documents, and personnel to assist in the search for the

information; it is a trove of knowledge on the city. As well as containing records of the past, it may accommodate immediate and temporary uses by tailoring its functioning to the festivals occurring in its immediate vicinity (as an example, a seminar relating to the historical roots of a particular facet of the festival may be held here). It is also a place where the future aspirations of individual citizens may be elucidated by providing a venue for intimate conferences with one's representative in the municipal government, the City Councillor (herein referred to as simply the Councillor) (Figs. 30 and 31).

The library is easily accessed via an elevator heading to a thin building on columns above the plaza at the top of the mounds. This is the Councillors Office Block. Consisting primarily of offices pushed towards the perimeter, it encapsulates many qualities the public attributes to the Councillor : one who holds the dignified role of public office (manifested in the location of his / her office in a building hovering above), yet is accessible and accountable to his/her constituents. For example, light emanating from the offices above indicates to the public that Councillor is present and working. Accessibility is demonstrated as well in the prominent elevator and stairs which lead down from the Councillors Office Block to the public plaza above the mound, a place of gathering which allows for the general public to congregate in the 
"sanctified" space beneath the offices. Councillors descend from the Office Block to the plaza below to take the path towards the Council Chambers for weekly sessions - this configuration provides a venue for members of the press to ask questions of the Councillors before and after

\section{Council Meetings.}

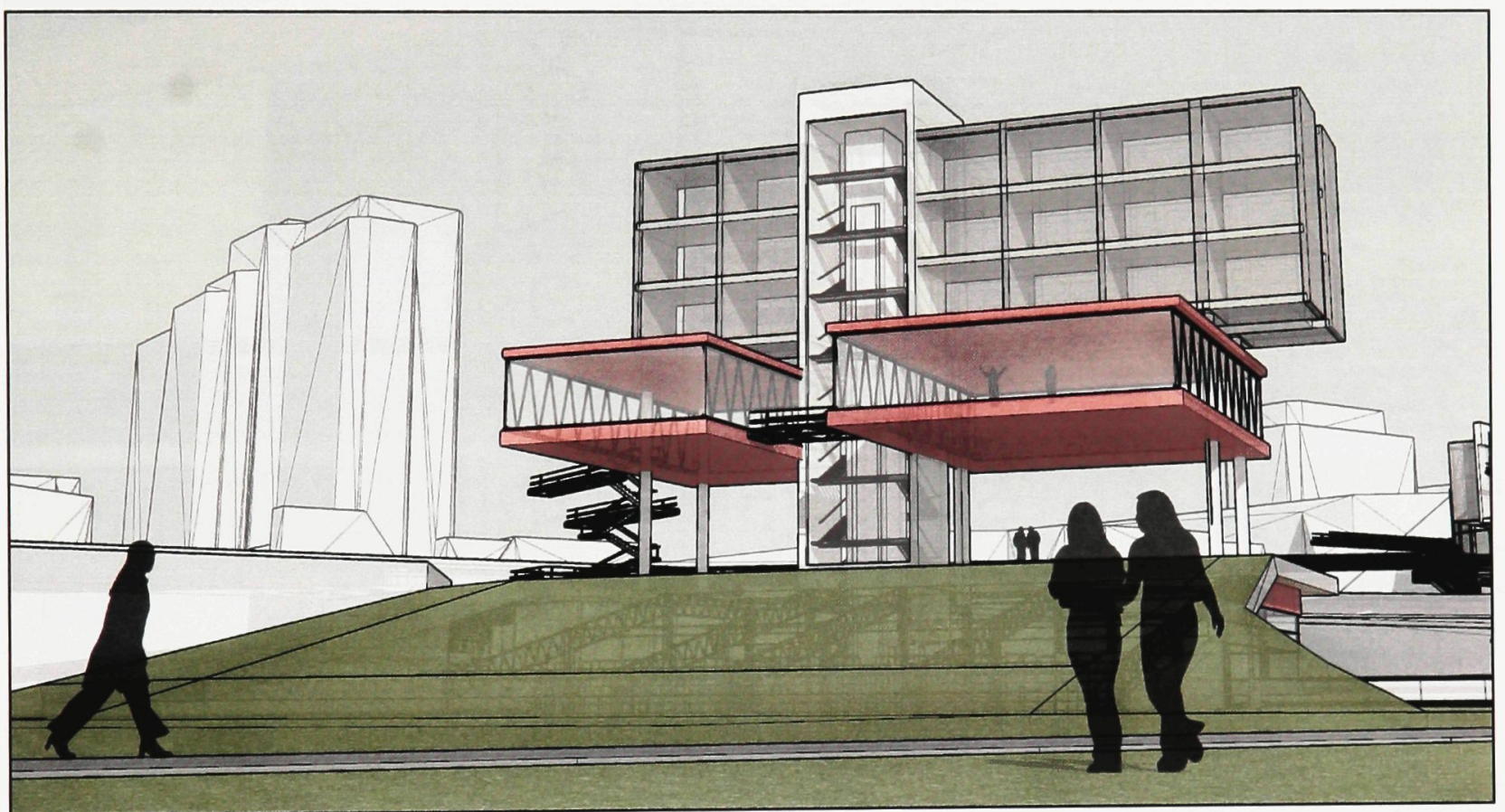

Directly beneath the Councillor's Offices are large multi-purpose rooms which are made accessible to various groups by appointment. Their uses may relate to the operations of the municipal government, but are not restricted to it; while groups may make presentations to Councillors in this space, or Councillors may use it as a meeting space, it may also be used by private individuals who hope to be granted a unique vantage point to take in local festivities.
Fig. 29. Perspective, New Ottawa City Hall Mound in the South Plaza.

The Councillors Office Block (and the associated multi-purpose rooms directly below them) floats above the mound, and the Library is buried beneath it. A set of stairs and an elevator connect the three elements. 

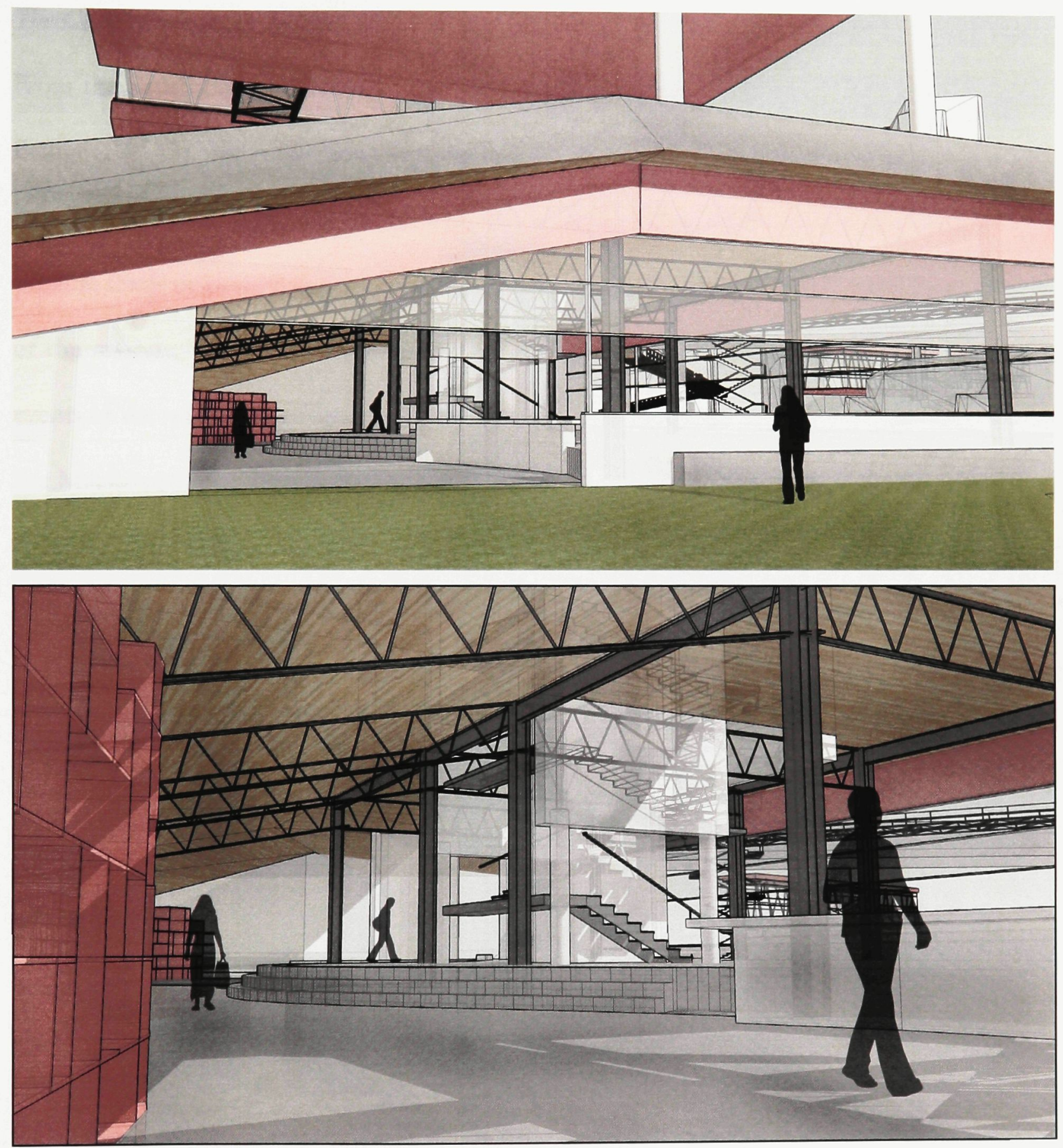

Figs. 30 and 31. Perspectives, New Ottawa City Hall.

Library beneath the mound in the South Plaza. The stairwell and elevator, a connection to the Councillors Office Block, the Plaza above and the multi-purpose rooms, feature prominently in the building. 


\section{The Canal Pedestrian Bridge}

From the South Plaza pedestrians may walk south over the Canal across the Canal Pedestrian Bridge (Fig. 32). The pedestrian may stop to enjoy the events of the seasons on the bridge - one may sit and watch boats sail beneath or skaters zip by. Moveable screens may be operated to provide shade or protect against gusty winds when necessary, attuning one to the idiosyncrasies of the seasons. The bridge allows even the onlooker to feel as if they are participating in the events of the season. The Canal Pedestrian Bridge terminates at the Tower and the west end of the Mackenzie King Pedestrian Walkway.

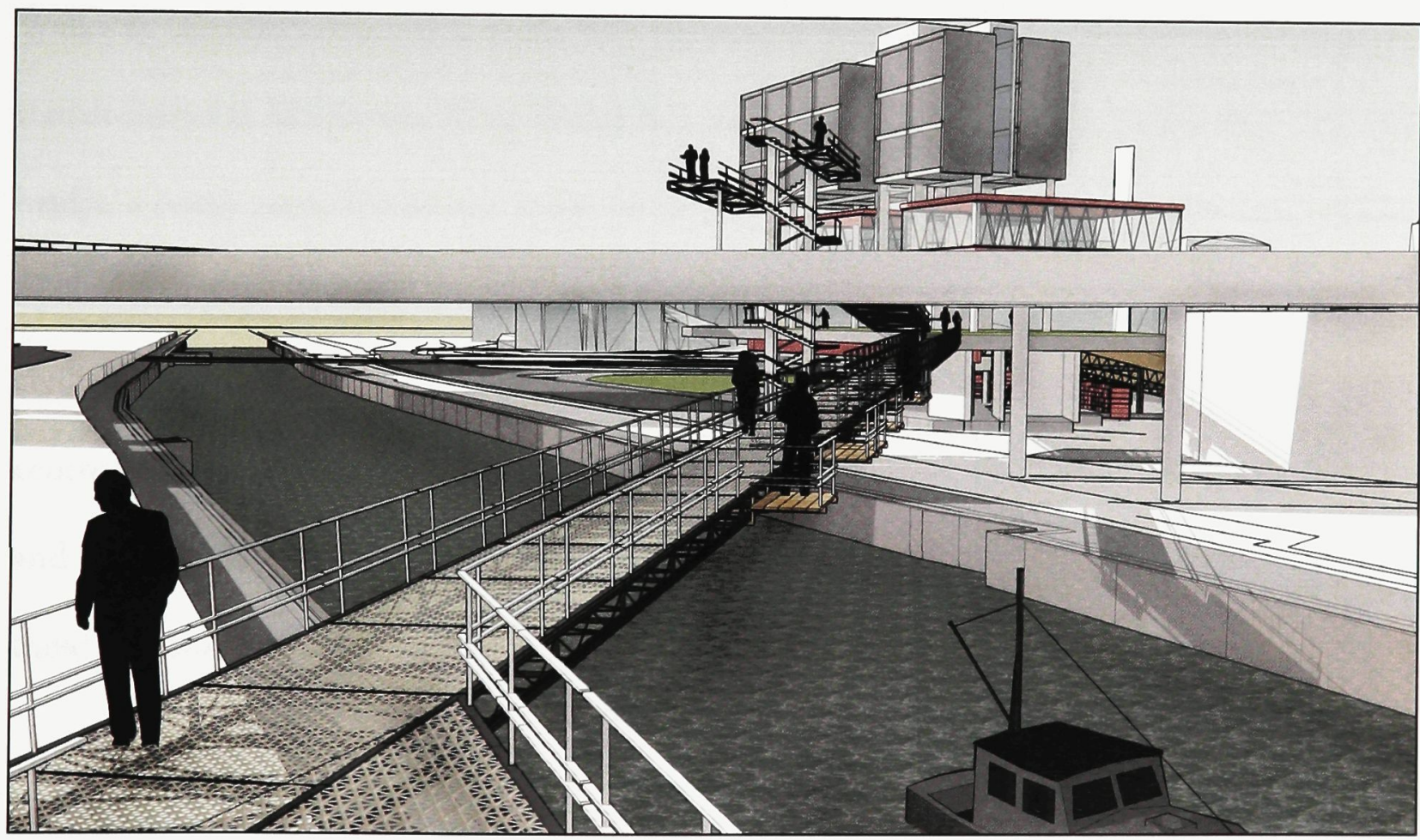

Fig 32. Perspective, New Ottawa City Hall. Canal Pedestrian Bridge.

Small wood plank ledges generate momentary pauses in pedestrian transit to reflect on the surroundings. 


\section{The Tower and the Mackenzie King Pedestrian Walkway}

City Halls have used tower components grant a citizen a singular view of the city in which he/she resides and implicitly reinforces the recognition of the areas which are governed by the institution ${ }^{15}$. The NOCH's Tower functions as well to provide the viewer with the only vantage where he/she is granted a singular view of the institution which governs him/her - here is the only point in the scheme where the units and their connections are all visible.

At the base of the Tower one may access the western end of the Mackenzie King Pedestrian Walkway (hereafter referred to as the MK Pedestrian Walkway), which follows the route of the transit-oriented Mackenzie King Bridge but rises above the level of the traffic (Fig. 33). The bridge services many functions: access to the Council Chambers for Councillors and civilian observers, access to the Administrative Offices and the Service Centre for Councillor and civilian uses, access to the popular shopping destination of the Rideau Centre and the urban centre beyond, and access to the Mackenzie-King Transit Hub. The rituals of civic governance and the private interests of individuals meet and overlap, depending on the varied schedules of these flux components (Fig. 34).

\footnotetext{
15 Towers are significant components of the $\mathrm{COCH}$, the FOCH addition, and the Edmonton City Hall, for example.
} 

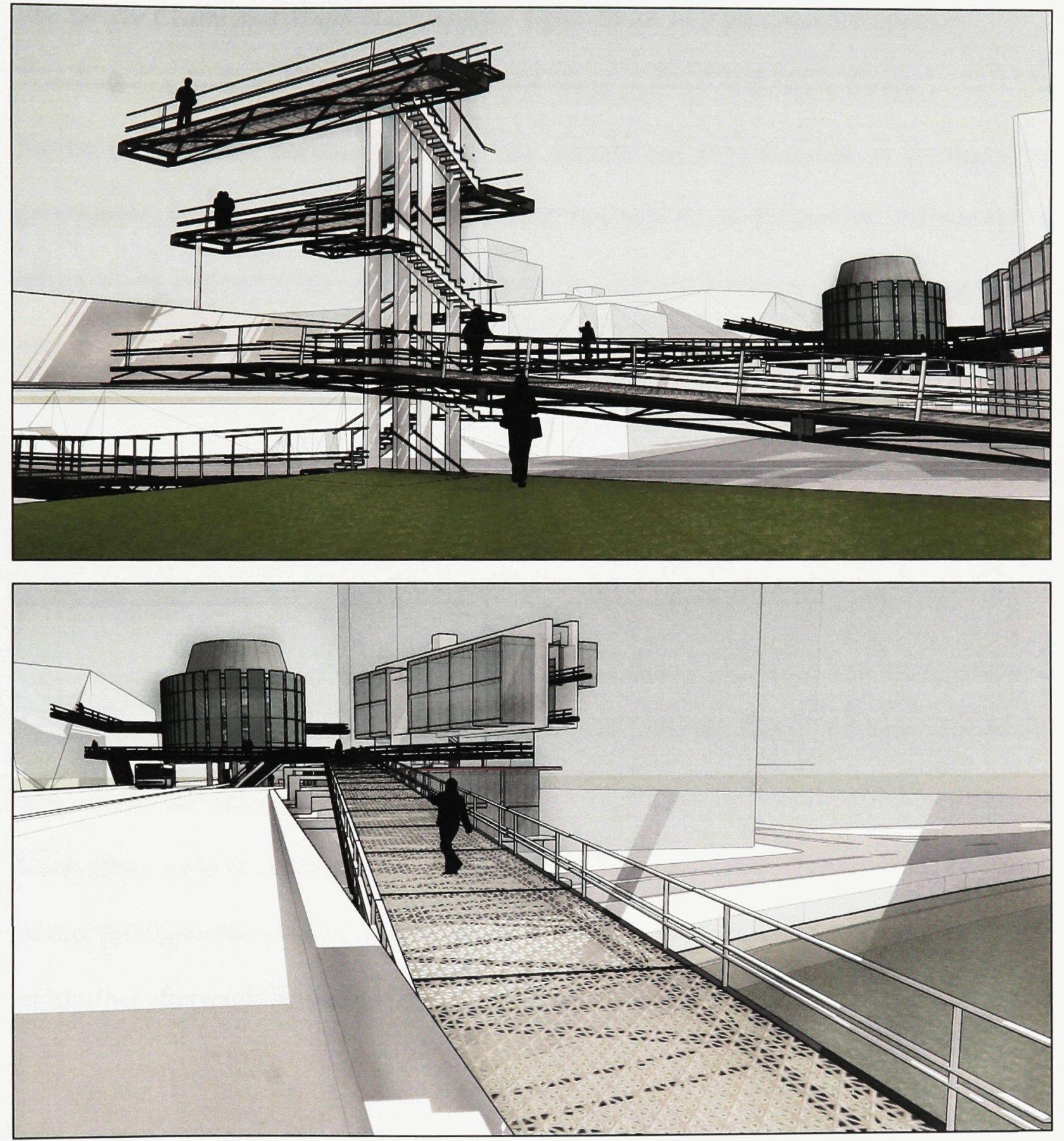

Fig 33. Perspective, New Ottawa City Hall. Tower, with ramp leading to the Mackenzie-King Pedestrian Walkway in the foreground.
Fig 34. Perspective, New Ottawa City Hall. Looking Westwards down the Mackenzie-King Pedestrian Walkway towards the Mackenzie-King Transit Hub, the Municipal Employee Office Block (to the right) and the Council Chambers (to the left). 
Traveling east from the Tower over the Canal along the MK Pedestrian Bridge leads to the Service Centre. Here individual citizens may inquire and request things of the municipal government, along with formally offering their opinions on its functioning. Administrative offices which respond to the requests made by the citizens are located above, and the citizen may directly access the office which offers the services he/she requires. The offices are highly visible and individually articulated so as to best show that the administrative force behind the smooth functioning of the institution is comprised of individuals. This transparency and articulation is displayed to the human and mass transit along Mackenzie King Bridge, as well as the vehicular traffic along Colonel By Drive, which passes below it (Fig. 35).

The Service Centre is situated between the Councillors Office Block and the Council Chambers. This implies the influence of the individual citizen in the executive process; it is possible that Councillors could be influenced by the findings of the Service Centre before sitting at council, or that the Councillors may receive feedback about a council meeting from constituents relayed to him/her afterwards by the Service Centre (Fig. 36). 

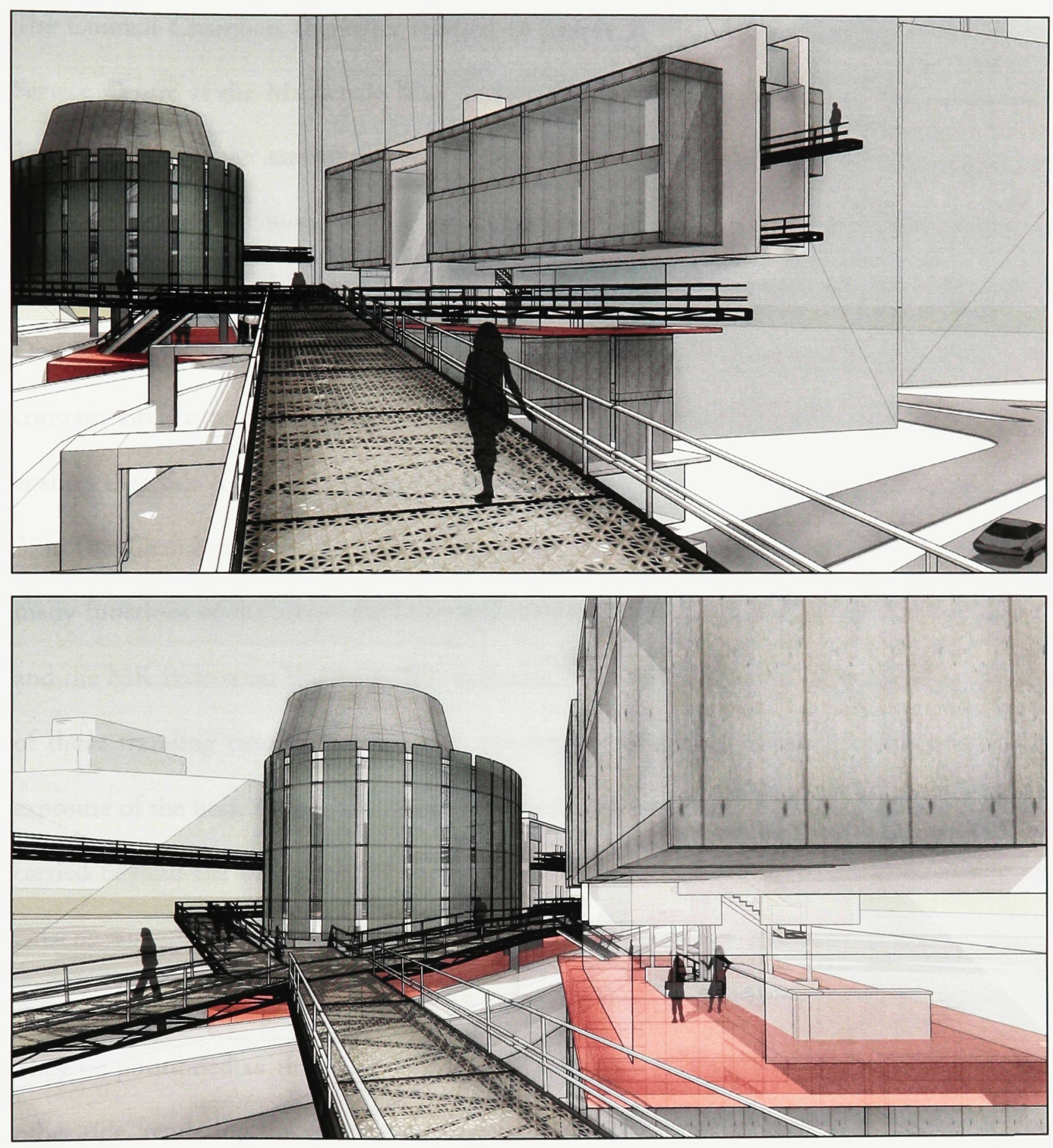

Fig. 35. Perspective, New Ottawa City Hall.

Looking Westwards down the Mackenzie-King Pedestrian Walkway. The articulated offices of the Municipal Employee Office Block jut out over Colonel By Drive below.

Fig. 36. Perspective, New Ottawa City Hall.

The Service Centre (at left in the image), located beneath the Municipal Employee Office Block and partially bordered by the Mackenzie-King Pedestrian Walkway, addresses inquiries from the public. It is in close proximity to the Council Chambers (at right in the image) 
The Council Chambers (hereafter referred to simply as the Chambers) sits just east of the

Service Centre at the Mackenzie King Transit Hub (hereafter referred to simply as the MK Transit Hub). As the executive organ of City Hall, it serves a foundational purpose in the institution, as the decisions made there determine how the city will operate. This implies a permanence to the node as its functioning is intrinsic to the continuance of the institution. Despite this, or rather in light of this, the Chambers is placed in a space of constant flux - the constant circulation through the space by transit users and the movement of transit vehicles ensures that this is a space qualified by speed, change, temporality and impermanence (Fig. 37). The Chambers takes the form of a volume wrapped by circulation which services the many functions of the area - the buses and rail lines, the Rideau Centre, the Service Center, and the MK Pedestrian Walkway. This enclosure by movement allows for incidental exposure of those traveling through the space to the events transpiring within the Chambers - the exposure of the node to this flux means that the discussions held within the Chambers will be carried beyond the boundaries of the node, de-territorialized and transmitted by individual citizens. To augment the potential for this incidental exposure, the volume of the Chambers will be perforated by small viewing voids accessible from the enclosing circulation pathways. They be positioned so that viewers may look across the Chambers through to voids on the other side, rendering the volume of the node translucent. These framed spaces group people 
together - these groups may then feel compelled to discuss the goings-on which they see.

Aside from these galleries, the Chambers will be enclosed by a translucent skin and lit from the interior, allowing the volume to act as a lantern or beacon, an indicator that an event of import is happening inside. Though the enclosure of the Chambers is present at the MK Transit Hub regardless of its use, this lighting allows for others to become aware of its activation through the temporary act of its inhabitation. 

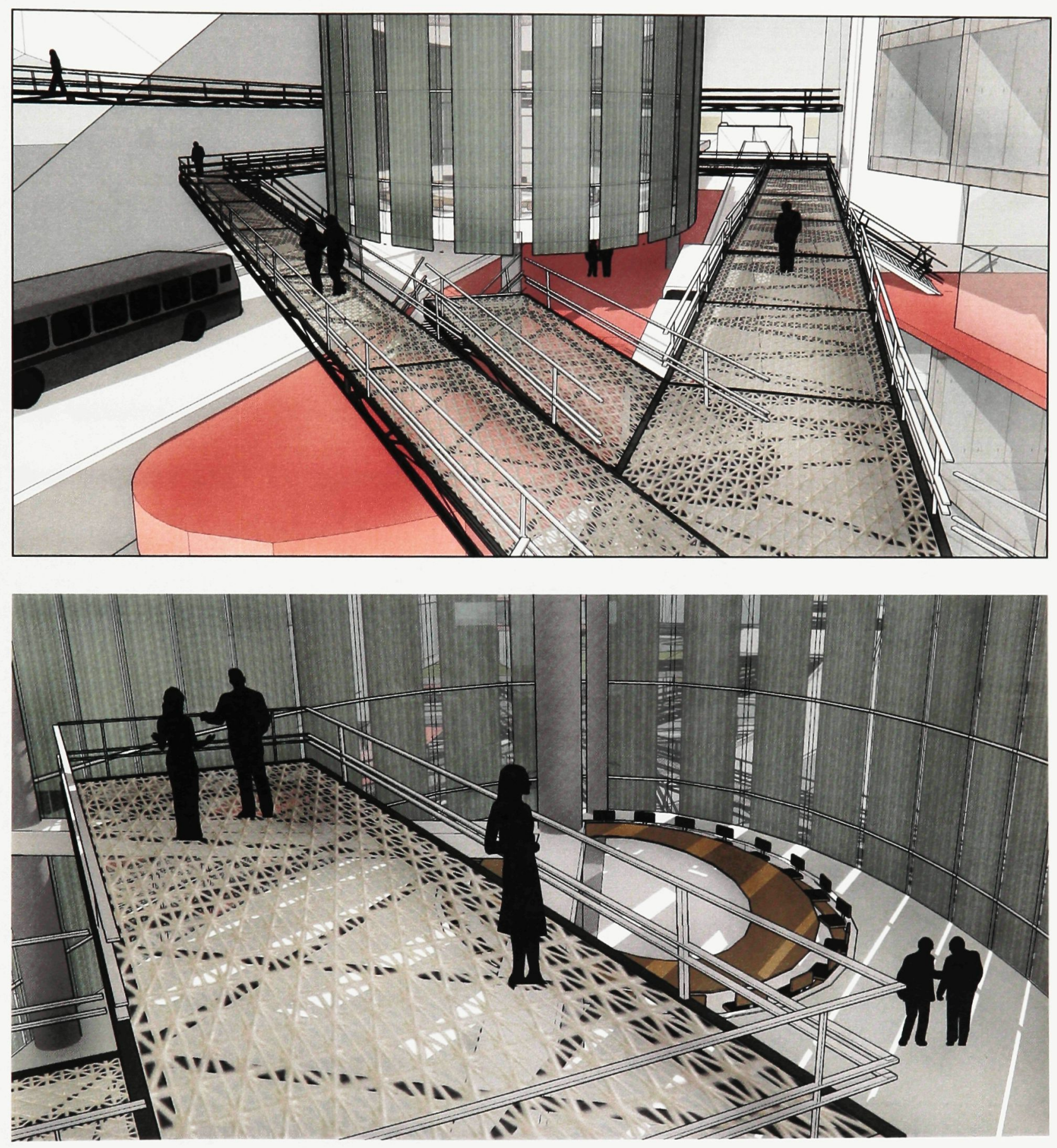

Fig. 37. Perspective, New Ottawa City Hall. The Council Chambers (at center in the image) hovers above a bus and train platform at the Mackenzie-King Transit Hub. Elevated walkways allow for glimpses into the volume of the Chambers.

Fig. 38. Perspective, New Ottawa City Hall. Council Chambers, interior perspective.

Elevated walkways carrying commuters encircle the Council Chambers. A walkway slipping into the volume of the Chambers acts as a viewing gallery for those interested in observing Council meetings. 
The inclusion of flux in building design has the ability to unseat the mono-functionalist determinisms evoked by traditional architectures of power. The nature of flux is that it is unique to its specific location as it is a factor of, and a response to, local environmental actors. As such, it evokes different responses from every such actor.

The proposed New Ottawa City Hall seeks to incorporate flux within an architecture that houses both a will to govern and a will to be receptive to a large population of local constituents. The approach taken by the author was to fragment an existing container of such a program, the Former Ottawa City Hall, and disseminate the constituent elements of the program throughout a large site in the city's urban center. The placement of the nodes and the opening up of the linkages between them allowed for a re-evaluation of the relationship between the institution and the local population. By allowing for elements of the existing urban infrastructure to 
penetrate the functioning of the City Hall, constituents are allowed to participate in the institution's operations. These constituents, who in previous incarnations of the City Hall building were formerly removed from such encounters, are able to evaluate the institution and transfer its discussions to broader areas (the proximity of the Council Chambers to the Mackenzie-King Transit Hub, for example, allows for such an occurrence). The opening of the City Hall to the flux of the surrounding infrastructure allows the institution a greater presence and understanding within the daily experiences of its constituents. It exists as well as a symbol of the greater civic community by embracing site-specific urban elements unique to downtown Ottawa, such as the Rideau Canal, Mackenzie-King Bridge, Rideau Centre and Confederation Park, as well as associated seasonal events and festivals.

The project acts as an exercise in the planning of a re-conceived civic institution, and as such there are levels of development which remain to be explored. The juxtaposition of the Nodes with existing conditions on the site work in a broad sense to integrate the functioning of the City Hall and its urban context. A finer examination of the functioning of each node, such as a mapping of the daily routines of the City Councillors within their Office Block and adjoining Library, could allow for the fleshing out of this integration at the level of the individual who passes through the New Ottawa City Hall. A refined architecture can then arise from the 
orchestrations of subtle moments of encounter between persons, such the incidental sighting of two individuals having a discussion in a moment of perceived solitude, seen through a single window strategically placed.

The orchestration of Nodes on a macro-level of site organization, coinciding with architecturalization of micro-moments of individual encounter, both contribute to the realization of the project's intents. The integration of the flux of the urban context with that of City Hall may then be conceived of as seamless, unifying the institution and its constituent areas as a larger civic organism. 


\section{CONCLUSIONS}

The New Ottawa City Hall is a work which attempts to reunite the institution with the population it represents. The strategy, in its essence, re-positions the building into a location where that population is dense and shifting in flux, due to the proximity of urban infrastructure connections and various points of civic interest. The New Ottawa City Hall opens itself up to this flux by breaking apart and allowing its internal operations to intermingle with it. It is a building in flux.

That is, it is a building located within a "context" of flux. The Nodes remain ever-present and stable as the movement of the city and its citizens flow around them. Can the building itself be an element of flux? What form would it take? The proposal's Nodes act as armatures for the actions performed within them; multiple programmes within single Nodes are possible (the use of the Multi-Purpose Rooms below the City Councillor Office Block can serve both 
governmental matters and festival functions, for example), but the variety of programmatic possibilities is still limited by certain functional roles the Nodes must play within the overall scheme. What if, instead, a broader array of possibilities was embraced, and an armature was created where all programmes may be accepted within its bounds?

As discussed earlier in this text, Rosalyn Deutsche posits the space of the public as being a place under constant re-definition and revision, where contestations and debate amongst it users unseat any permanent ideological assumptions and programmatic delineations. Would such a place not truly be a civic space, where the desires and values of citizens may be defined through the constant flux of re-definition? And the structure that houses that space, must it be as dynamic and open to change, even in the physical sense, as that which it "holds" within?

If so, such a structure is, on some levels, the antithesis of the monument, the unchanging, unquestionable representation of foundational ideals. This structure holds change and redefinition as ideals, a place where individuals may debate assumptions and the building, in whatever "form" it takes, shifts to respond to these debates. This structure is a building in flux. 
Blomley, Nicholas. "Law, Property, and the Geography of Violence: The Frontier, the Survey, and the Grid." Annals of the Association of American Geographers. 93(1) $2003: 121$ - 141.

Canada. National Research Council. Public Policy And Transit Oriented Development: Six International Case Studies. 1996.

“Criticism : Ottawa City Hall." The Canadian Architect. 3.11 (1959) : 29-39.

Davis, Mike. "Fortress Los Angeles: the Militarization of Urban Space." School of Literature, Communication \& Culture - Georgia Institute of Technology. 20 April $2006<$ http://www.lcc.gatech.edu/ broglio/1101/davis.html>.

Deutsche, Rosalyn. "Agoraphobia." Evictions : Art and Public Politics. Boston : The MIT Press. 268 - 367.

Dovey, Kim. Framing Places: Mediating Power in Built Form. London: Routledge, 1999.

Foucault, Michel. “Of Other Spaces : Heterotopias.” Michel Foucault, Info. 29 Oct. $2006<$ http://foucault.info/documents/heteroTopia/ foucault.heteroTopia.en.html>.

Frampton, Kenneth. Modern Architecture : a critical history. London: Thames and Hudson, 1992.

Gardiner, Michael. Critiques of Everyday Life: An Introduction. London : Routledge, 2000.

Glassford, Mark. “Modernism in Canada : Three Post War City Halls, 1953-1960.” Diss. Carleton U, 2003. 
Grönlund, Bo. "Lefebvre’s Second Ontological Transformation of Space : Absolute, Abstract and Differential Space." Bo Gronlund on Henri Lefebvre - Urbanity : Lived Space and Difference. 1993. University of Copenhagen. 3 Oct. 2006 <http://hjem.get2net.dk/ gronlund/Absolute_space_etc.html>.

Jencks, Charles. "Hetero-Architecture for the Heteropolis." Architecture of Fear. Ed. Nan Ellin. New York : Princeton Architectural Press, 1997. $217-225$.

Jencks, Charles. Heteropolis: Los Angeles, The Riots and the Strange Beauty of Hetero-Architecture. New York : St. Martin's Press, 1993.

Jencks, Charles. "The LA Style and the Heteropolis." Arcspace. 27 Feb. $2006<$ http://www.arcspace.com/calif/intro/intro.htm>.

"Krzysztof Wodiczko." Art History - Concordia University. 5 Nov. 2006 <http://art-history.concordia.ca/eea/artists/wodiczko.html>.

Ledrut, Raymond. "Speed and the Silence of the City." The City and the Sign : An Introduction to Urban Semiotics. Ed. Mark Gottdiener and Alexandros Lagopoulos. New York : Columbia University Press, 1986.

Lefebvre, Henri. The Production of Space. Malden, MA : Blackwell Publishing, 1991.

Lewis, Jennifer, Andrew Roberts and Louise Warriar. "Surveillance: An analysis of Jeremy Bentham and Michel Foucault and their present day relevance.” 2002. 13 Nov. 2006 <http://www.mdx.ac.uk/www/study/ybenfou.html>.

Mayne, Thom. Morphosis. Vol. 3. New York : Rizzoli International Publications, 1999.

Mayne, Thom. Morphosis : Connected Isolation. New York : St. Martin’s Press, 1993. 
Mayne, Thom. "Crawford Residence : Architectural Statement." The Pritzker Architecture Prize. The Hyatt Foundation. 11 Jan. 2007 $<$ http://www.pritzkerprize.com/164/pritzker2005/crawfordresidence.htm>.

Newman, Oscar. Creating Defensible Space. Washington : GPO, 1996.

Newman, Oscar. Defensible Space : people and design in the violent city. London : Architectural Press, 1972.

"Pedestrian Sundays in Kensington Market." P.S. Kensington. 15 Nov. 2006 <http://www.pskensington.ca/>.

Pindorama. 12 Aug. 2007 <http://www.pyndorama.blogger.com.br/s16.JPG>.

"Reclaim the Streets!" Reclaim the Streets (London). 21 Jan. $2007<$ http://rts.gn.apc.org/>.

Richter, Dagmar. “Spazieren in Berlin.” Assemblage. 29 (1996) : 72-85.

Sewell, John. "The City Hall Shuffe." Eye Weekly. 27 Jan. 2005. 13 July. 2006 <http://www.eye.net/eye/issue/issue_01.27.05/city/ citystate.php>.

Sparke, Matthew. In the Space of Theory. Minneapolis, MN : University of Minnesota, 2005.

"Spoof Ads." Adbusters. 12 Dec. 2007. <http://adbusters.org/spoofads/index.php>.

“The Superblock.” Brasilia. 1996. Macalester College, Minnesota. 12 Aug. 2007 <http://www.macalester.edu/courses/geog61/jmoersch/ sqs1.html>. 
"Toronto City Hall : a brief history." City of Toronto. 2007. City of Toronto. 13 Feb. 2007. <http://www.toronto.ca/city_hall_tour/ history.htm>.

“Transitway Map." Public Transit in Ottawa. OC Transpo. 10 Jan. 2007. <http://www.octranspo.com/mapscheds/Transitway/tway map_menuE.htm>.

Vidler, Anthony. The Architectural Uncanny: Essays in the Modern Unhomely. Boston: The MIT Press, 1994.

Vidler, Anthony. Warped Space. Boston: The MIT Press, 2001.

Wight, Adam. "City of Quartz.” Revolve. 24 Apr. 2006 <http://www.ludd.net/essays/davis.html>. 


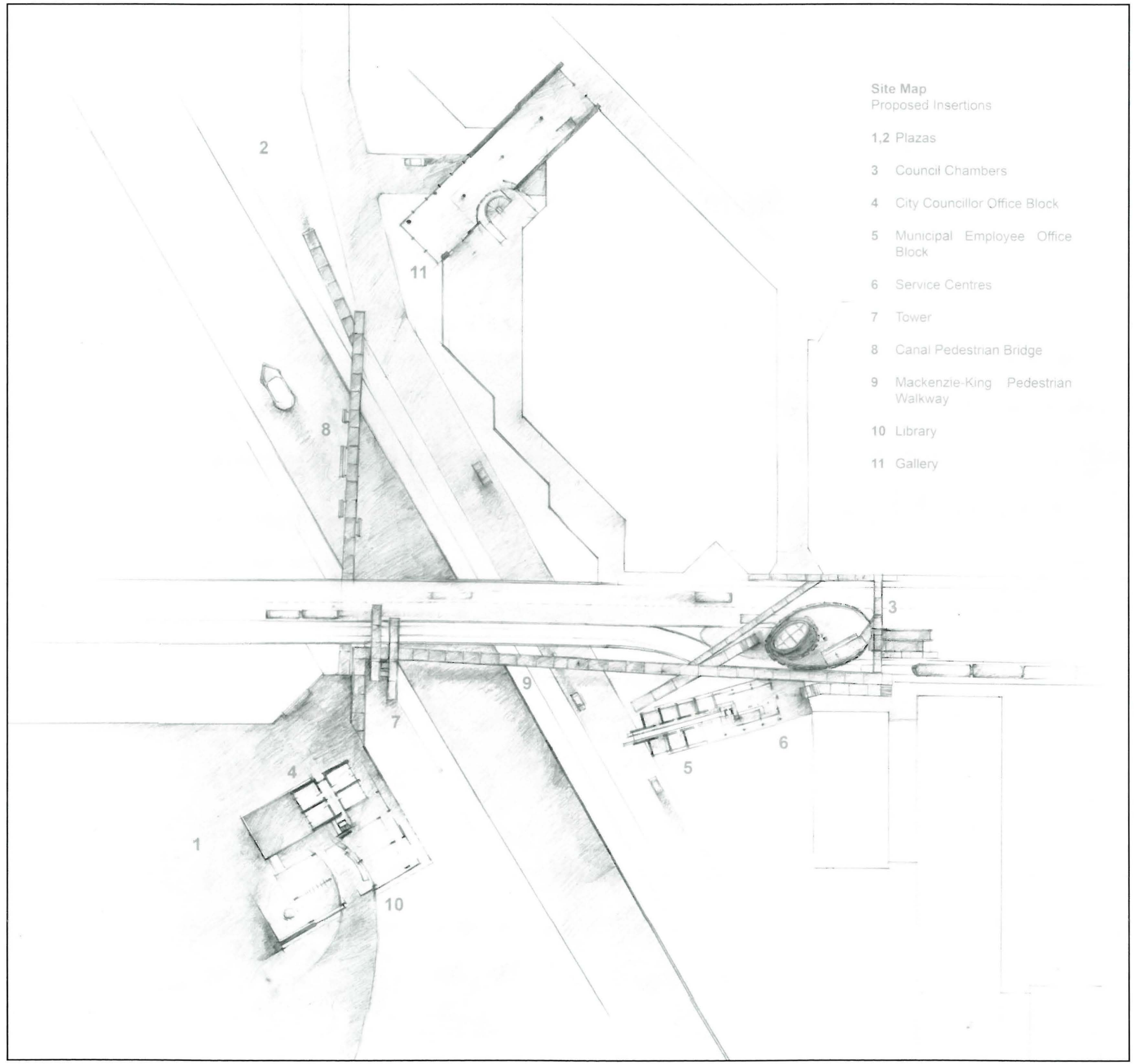

Plate 1. Conceptual Site Plan, New Ottawa City Hall.

Plans are overlapped and cut away to display the connections between the Nodes and the existing urban infrastructure found on the site (Drawn by the author). 


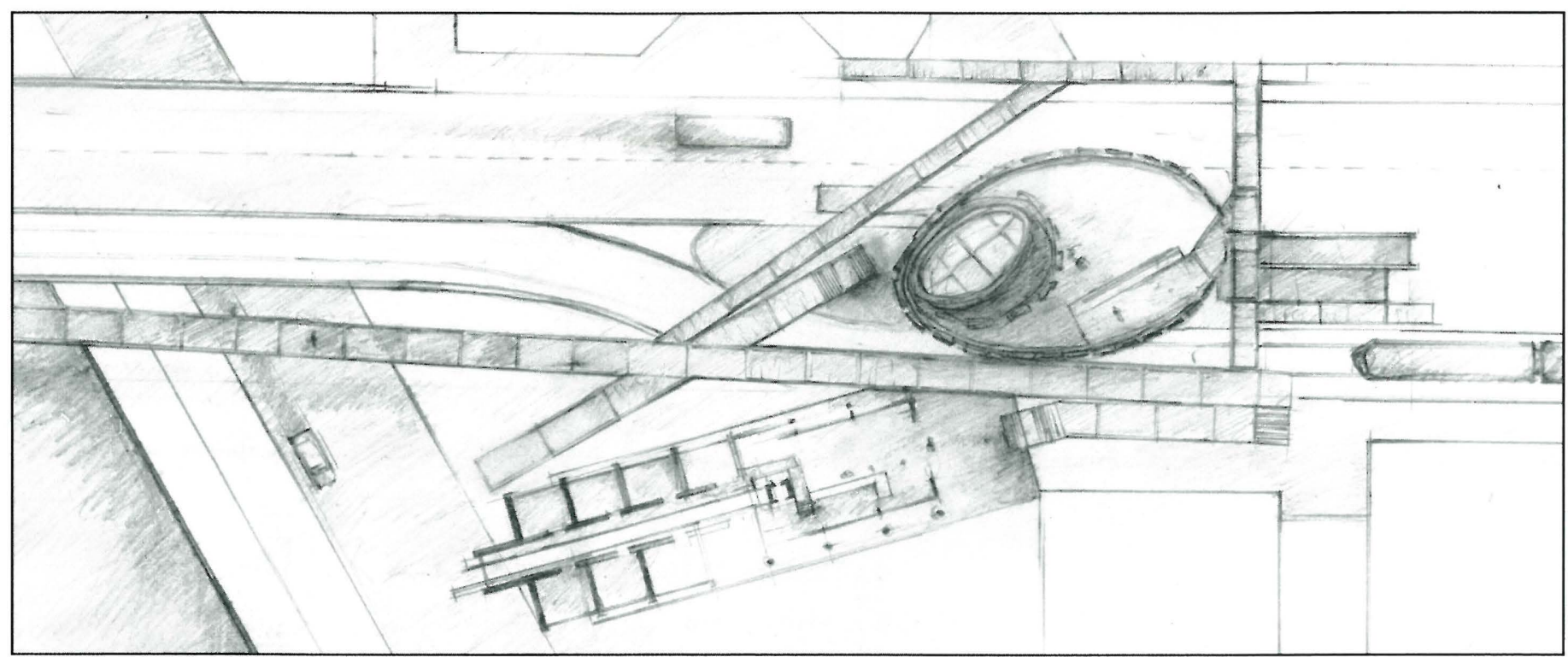

Plate 1, detail 1.
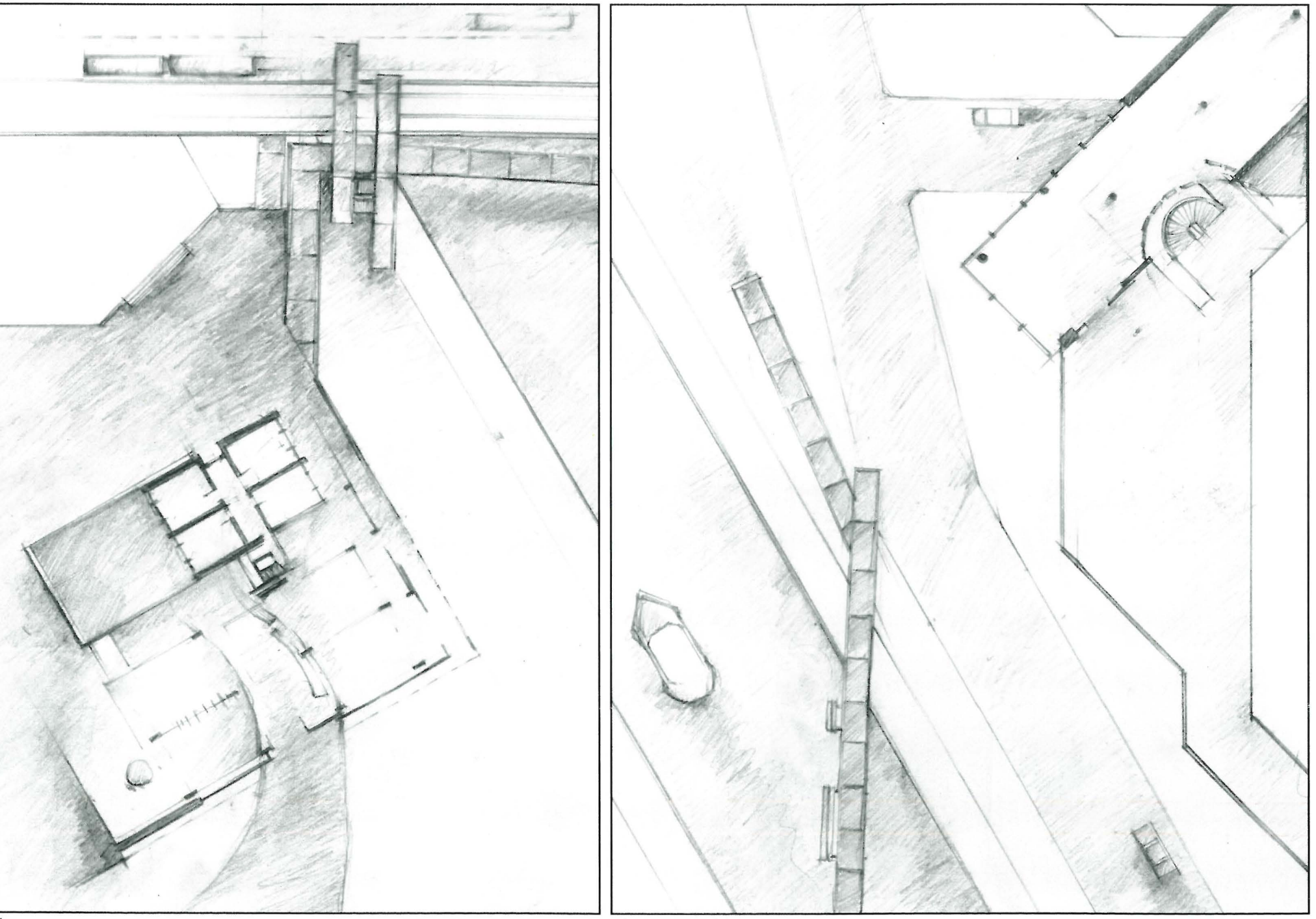

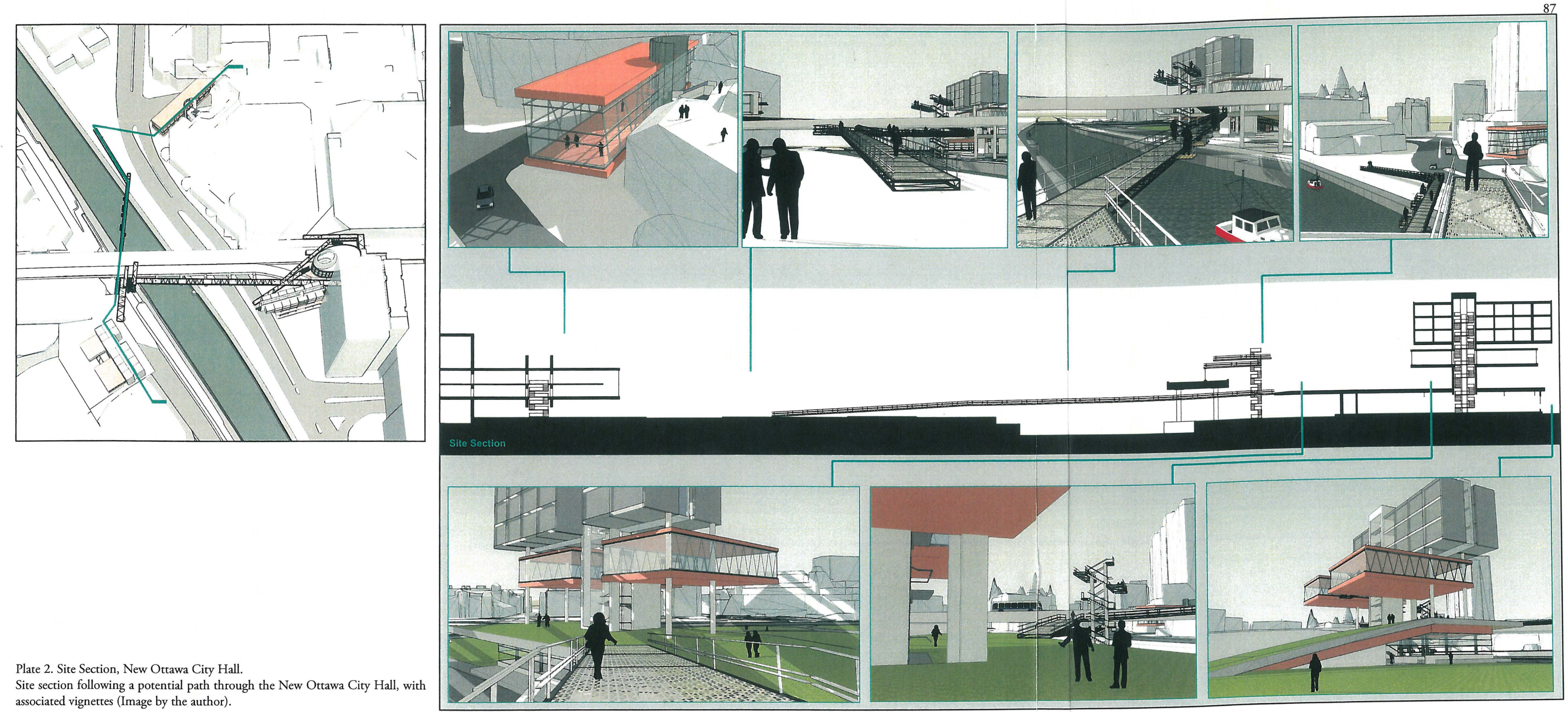

Plate 2. Site Section, New Ottawa City Hall.

Site section following a potential path through the New Ottawa City Hall, with associated vignettes (Image by the author). 

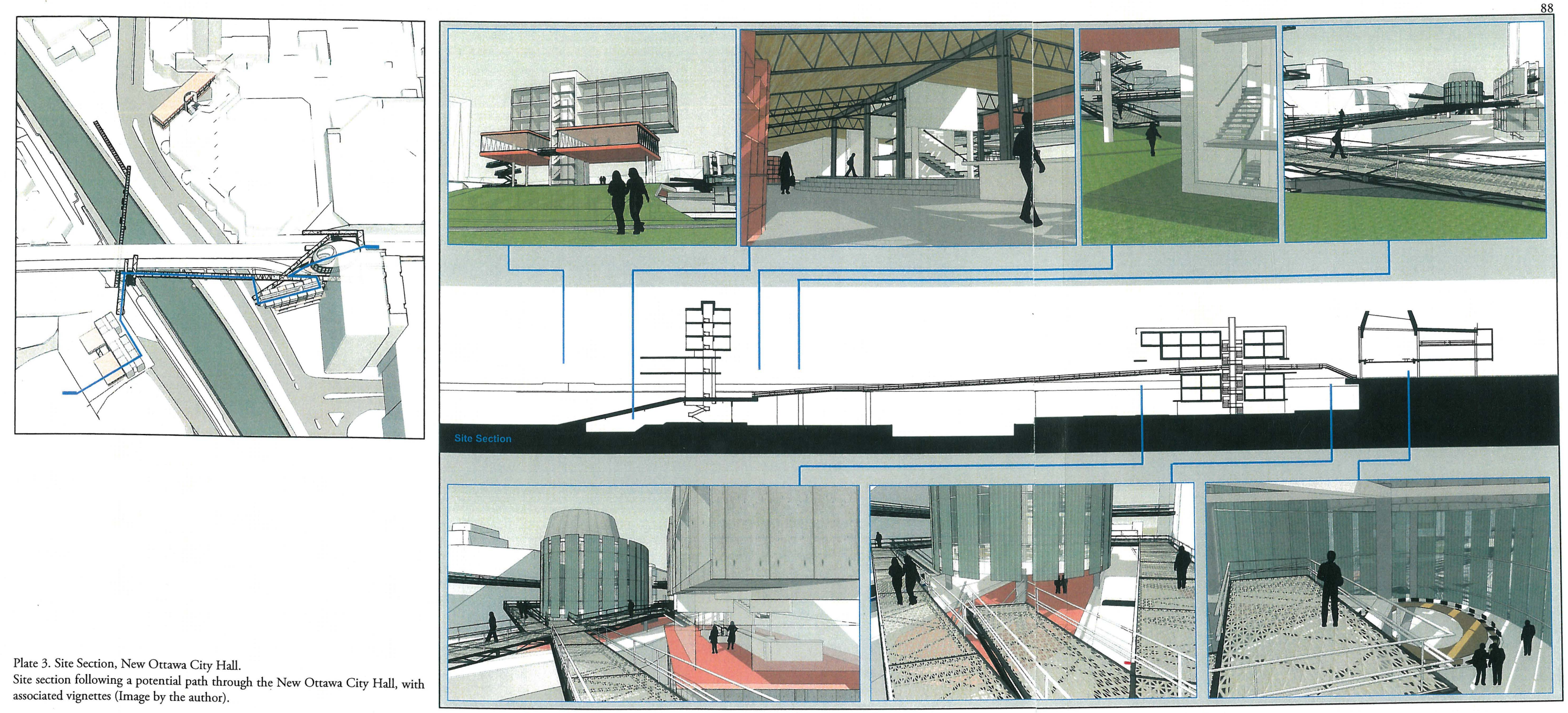

Plate 3. Site Section, New Ottawa City Hall. 


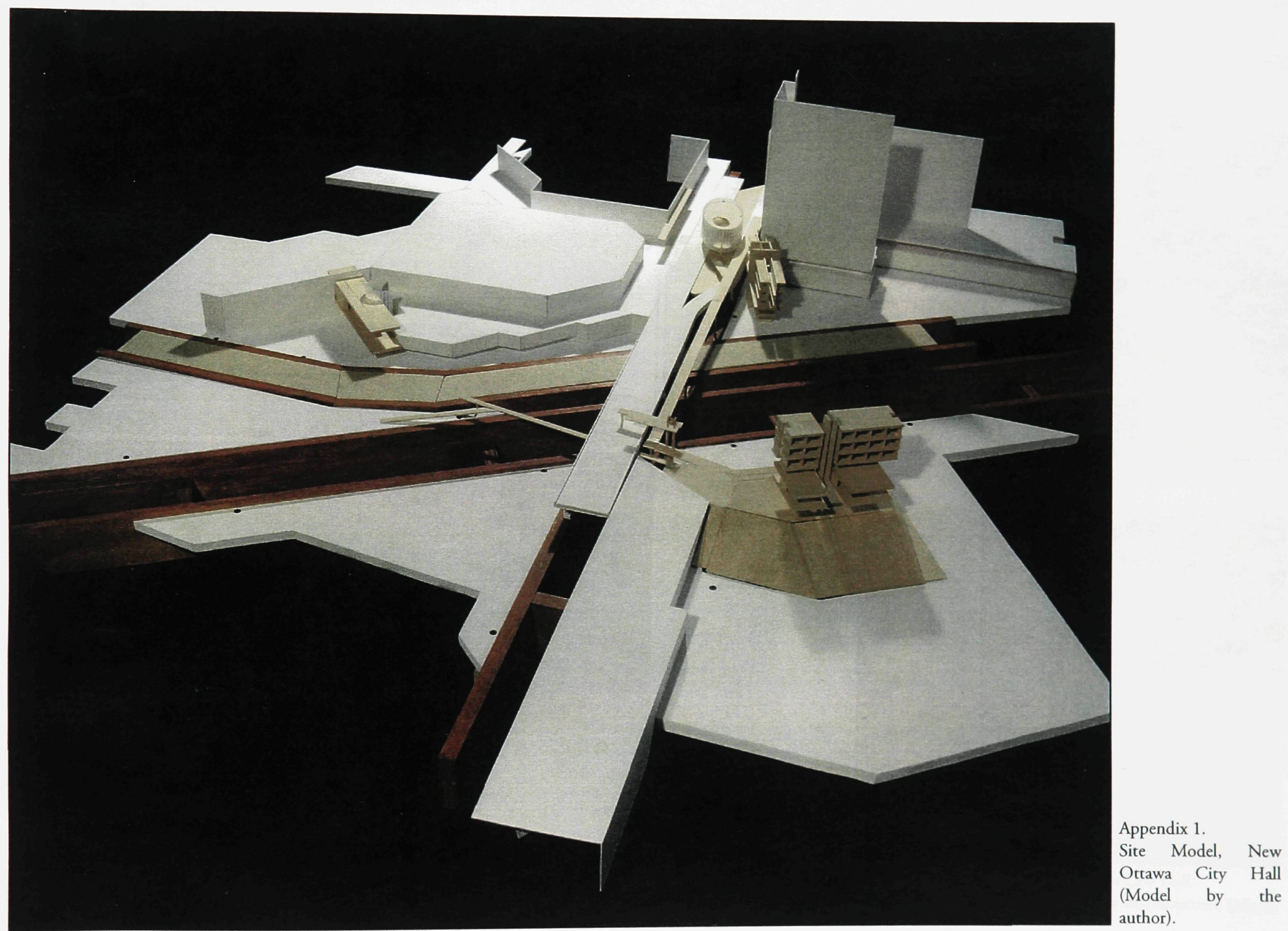



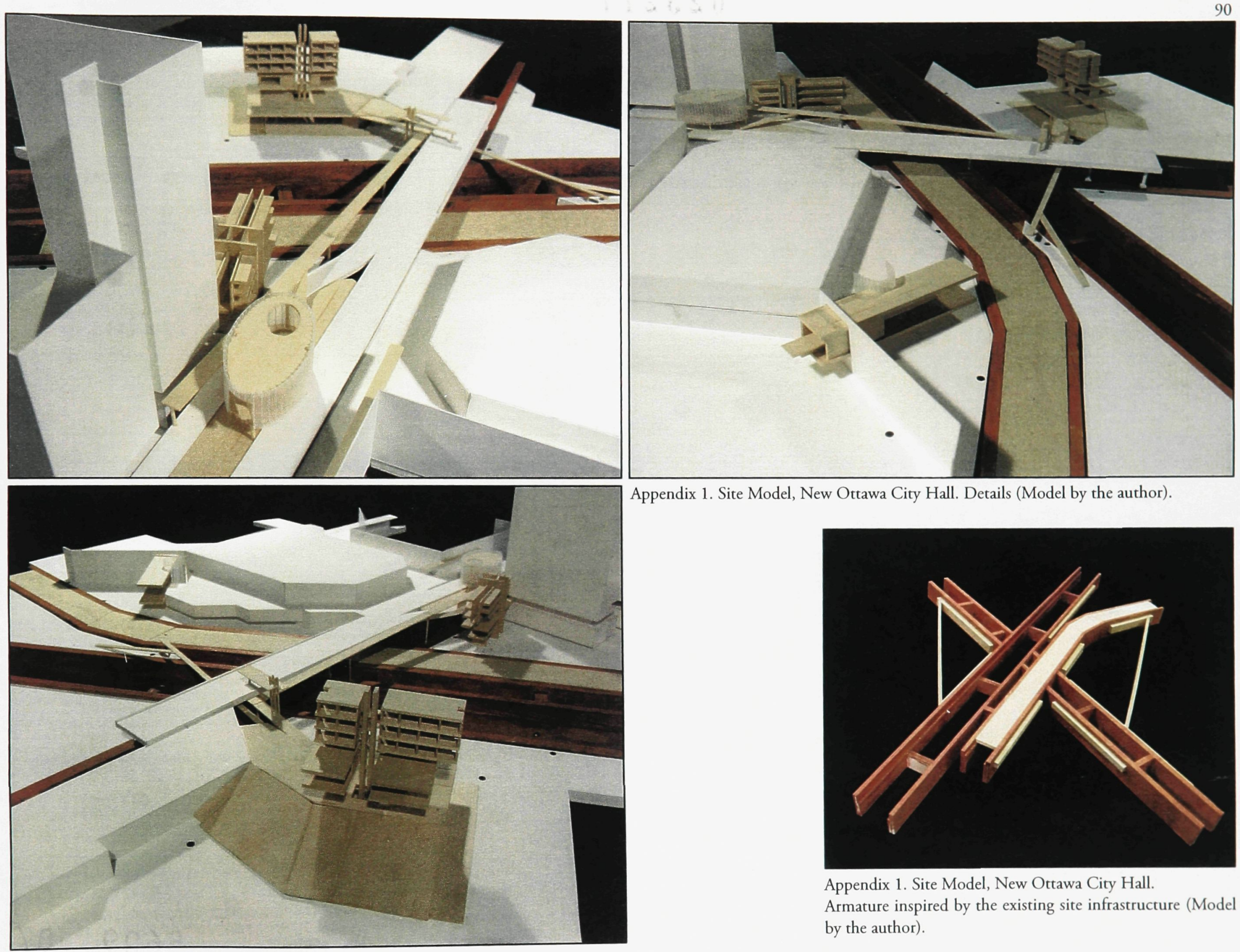

Appendix 1. Site Model, New Ottawa City Hall.

Armature inspired by the existing site infrastructure (Model by the author) 